\title{
Behaviour and Failure of Steel Columns Subjected to Blast Loads: Numerical Study and Analytical Approach
}

\author{
Haitham Al-Thairy (iD \\ Civil Engineering Department, College of Engineering, University of Al-Qadisiyah, Al Diwaniyah, Iraq \\ Correspondence should be addressed to Haitham Al-Thairy; haitham.althairy@qu.edu.iq
}

Received 19 June 2017; Accepted 26 December 2017; Published 11 March 2018

Academic Editor: Fabrizio Sarasini

Copyright (C) 2018 Haitham Al-Thairy. This is an open access article distributed under the Creative Commons Attribution License, which permits unrestricted use, distribution, and reproduction in any medium, provided the original work is properly cited.

\begin{abstract}
The main objective of this study is the numerical simulation of the behaviour and failure patterns of steel columns under blast loads using the dynamic finite element package ABAQUS/Explicit. A numerical model is suggested and validated against published experimental tests on full-scale wide-flange steel columns subjected to dynamic blast loads under constant axial compressive force. Afterwards, the validated model is used to investigate the effect of important parameters on the behaviour and failure patterns of steel columns under blast pressure through an extensive parametric study. The parameters include the blast impulse, the blast energy, the blast load, the blast duration, the column boundary condition, the column slenderness ratio, and the blast direction. The conclusions extracted from this parametric study may be used to develop a thorough understanding of the behaviour and failure of steel columns subjected to blast load which, in turn, could lead to a more accurate practical design procedure. The study also presents derivations and validations of a proposed analytical approach to calculate the critical blast impulse at which a steel column losses its global stability. Comparison between the critical impulse-axial force curves obtained from the proposed equation and that extracted from numerical simulations indicates the validity and feasibility of the proposed equation.
\end{abstract}

\section{Introduction}

Over the past few decades, many civil engineering structures have been subjected to explosions from terrorist attacks. The blast load and blast impulse generated from these explosions have caused failure to the structural members near to the detonation locations such as ground floor slabs, walls, and ground floor columns. Failure of such members can result in catastrophic consequences and progressive failure and collapse of the whole structure. Recent building standards and codes deal with such problems using approximate and conservative approaches. However, for accidental dynamic loads, a more accurate method needs to be developed and used in practical design.

For instance, Section 5 of Eurocode 1 part 7 [1] suggests that, for structures vulnerable to blast loads which may induce failure, a key element of the structure (such as a ground floor column in multistorey buildings) must be designed to resist the blast load without any failure. In addition, EC1 allows the use of an approximate analysis at which the blast load can be idealized a static load. The UFC manual for blast design [2] presents methods of design for protective construction used in facilities that are prone to explosions. The suggested methods are empirical and approximate and are intended to be used in specific blast scenarios such as the external explosions of partially open cubicles and interior explosions [2]. Other blast scenarios, such as external bumps containing highly explosive materials, are not addressed in this manual. Moreover, previous research studies $[3,4]$ have shown that the suggested beam-column interaction formula by UFC manual overestimates the column design capacity for high ranges of ductility ratios. The ASCE specifications [5] have also presented guidance on how to characterize the blast pressure in the design of structures in petrochemical facilities. However, all blast load calculation procedures use empirical formulae which neglect the dynamic nature of the blast pressure which may have a significant effect on the behaviour and failure of the structure. 
It is obvious that all the abovementioned methods neglect the dynamic characteristics of the blast load and its effects on the behaviour and failure of the structure (such as the blast duration, the blast impulse, the blast energy, the strain rate effect, etc). Moreover, for structural column under axial compressive load, the work generated by the axial load is not included in any of the above methods.

The need for more thorough understanding of the behaviour of civil engineering structures subjected to blast load has been well recognized by the engineering community, and a considerable amount of research has been published in this field of study. Within this research, the experimental study of Meknes and Opat [6] has identified plastic mechanism failure, tensile rupture failure, and shear failure as possible failure modes of fixed-fixed beams subjected to lateral impulsive load. Thereafter, Chen and Yu [7] have found that, the preaxial load increases the critical impulsive velocity for the tensile tearing failure mode and makes the beam more prone to failure due to transverse shear failure mode. However, the effects of local deformation and axial compressive loads were not included in the analysis of Chen and Yu.

Chen and Liew [8] have adopted mixed approach to numerically simulate steel columns subjected to combined blast and fire to minimize the running time of the analysis. Shell elements were used to model columns subjected to direct blast while beam element was utilized to model the rest of the structure. It was found that, under considerable values of the blast load, shear failure could occur near the base of the column. It was also concluded that using beam elements to model steel columns under blast load gives conservative results when compared with shell or solid elements because beam elements cannot capture the local response of the column.

The effect of axial compression on the behaviour of structural steel columns under blast loads was also investigated by Shope [9] who presented a numerical and analytical study to predict the critical impulse of steel columns subjected to blast loads. However, only beam element was used to model the column in the numerical model which may present unrealistic behaviour and failure of the columns particularly if local deformation and buckling occurred as confirmed by Chen and Liew [8].

Lee et al. [10] have suggested a new numerical approach to simulating the local behaviour of wide-flange steel columns subjected to blast loading. The suggested approach uses computational fluid dynamics (CFD) to simulate the complex air blast-structure interaction. However, no gravity load or axial load was applied to the columns during the blast analysis. Moreover, no failure or fracture of the material was simulated to allow observation of the large deformation of the columns.

Nassr et al. [4] have carried out experimental tests on axially compressed steel columns subjected to direct blast. Two different section sizes were used in the blast tests subjected to axial compression load which was selected to be $25 \%$ of the design compressive force. It was concluded that, for the applied level of the axial load, it is necessary to account for the axial load effect during the plastic phase of the column behaviour. However, for the steel columns subjected to high values of axial compressive load, the above conclusion may not be valid. Nevertheless, these test results may be used in the validation of numerical or analytical models.

Al-Thairy [11] has recently presented a single degree of freedom analysis study to predict the maximum lateral deflection of steel columns under blast load taking into consideration the effects of axial compression load and strain rate on the lateral resistance of the column. However, the suggested method only considers the global behaviour of the column neglecting the effect of local failure such as shear and tensile failure on the response of columns.

The research aims to extend the abovementioned studies to gain a comprehensive understanding of steel column behaviour under dynamic blast. To achieve this aim, a numerical model for simulating the global and local behaviour and failure modes of steel columns subjected to blast load using the finite element package ABAQUS/Explicit will be presented and validated using the experimental tests of Nassr et al. [4]. Thereafter, the validated numerical model will be used to examine the effects of several important parameters on the behaviour of steel columns subjected to blast pressure under different axial load values.

\section{The Numerical Model}

This section presents a description and validation of the ABAQUS/Explicit model used for simulating the behaviour and failure of isolated steel columns under blast load. The validation is necessary to ensure the correct implementation of the simulation procedure so that the suggested model can be used to generate extensive numerical results through parametric studies for the development of a design method.

Nassr et al. [4] have conducted experimental tests on W-shape steel columns with total length of $2413 \mathrm{~mm}$ and using two section sizes (Table 1). The top end of each column was pinned so that the axial and lateral movements were restrained (pin support) whereas only the lateral movement was prevented at the bottom end (rolled support) as shown in Figure 1. The columns were first axially precompressed until the static equilibrium was achieved and then subjected to a direct explosion using different explosive charges and different stand-off distances causing moment about the strong and weak axes of the columns. The value of the axial compression load was selected in all tests to be $25 \%$ of the design axial compressive static force determined according to AISC LRFD specification [5]. Two test cases were selected in the present validation examples because they involved plastic deformation and global instability as shown in Table 1. Figure 1 shows the steel columns used in tests along with ABAQUS model.

2.1. Model Description. C3D8R element provided by ABAQUS [12] was used to model the steel column. Based on the mesh sensitivity analysis shown in Figure 2, the element size of the columns was $20 \mathrm{~mm}$ along $0.5 \mathrm{~m}$ of the column midspan and the column ends to ascertain an accurate 
TABLE 1: Geometrical properties, loading conditions, and test results of the steel columns used in the validations [4].

\begin{tabular}{lcccccccc}
\hline Test symbol & Section & Blast direction & $k L / r$ & $P_{\text {axial }}(\mathrm{N})$ & $P_{\max }\left(\mathrm{N} / \mathrm{mm}^{2}\right)$ & $t_{d}(\mathrm{~ms})$ & $\operatorname{Impulse}(I)\left(\left(\mathrm{N} / \mathrm{mm}^{2}\right) \times \mathrm{sec}\right)$ & $\Delta_{\max }(\mathrm{mm})$ \\
\hline $4 \mathrm{C} 1$ & $\mathrm{~W} 150 \times 24$ & $x-x$ & 38 & 270000 & 4.283 & 2.1 & 0.003174 \\
$5 \mathrm{C} 1$ & W $200 \times 71$ & $x-x$ & 27 & 640000 & 2.098 & 8.4 & 0.003144 & $32.8^{* *}$ \\
\hline
\end{tabular}

$P_{\max }=$ maximum value of blast pressure $\left(\mathrm{N} / \mathrm{mm}^{2}\right) ; t_{d}=$ time duration of the positive blast pressure; ${ }^{*}$ instability deformation; ${ }^{* *}$ yielding and plastic deformation.

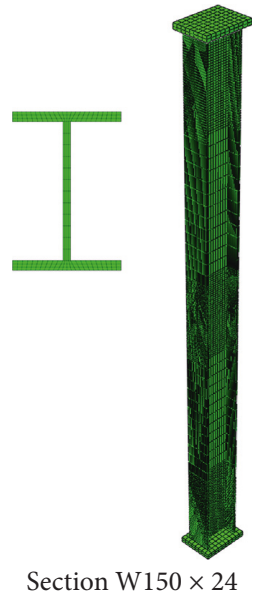

(a)

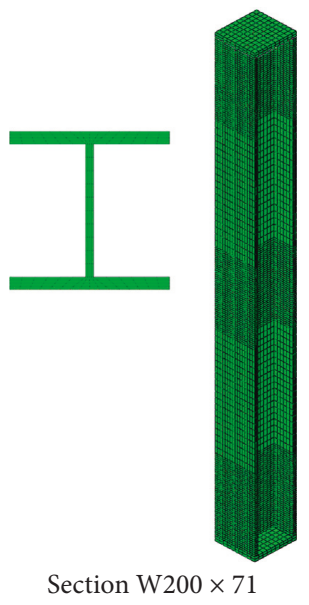

(b)
FIgURE 1: Numerical models used to simulate steel columns' behaviour.

simulation of the local failure at these locations due to the stress concentration [13]. For the rest of the column, the size of the element was increased to be $50 \mathrm{~mm}$ as shown in Figure 1. The column supports' condition was simulated by constraining and releasing the corresponding degrees of freedom at each end. The isotropic classical metal plasticity model provided by ABAQUS/Explicit was used to model the material behaviour of the steel column. The density, modulus of elasticity, and yield stress of steel were set to be $7850 \mathrm{~kg} / \mathrm{m}^{3}$, $206000 \mathrm{~N} / \mathrm{mm}^{2}$, and $470 \mathrm{~N} / \mathrm{mm}^{2}$, respectively, with Poisson's ratio taken as 0.3 [4]. Cowper-Symonds equation was used to account for strain rate effects using material parameters of $D=40.4 \mathrm{~s}^{-1}, q=5[14,20]$.

To detect the possible local shear damage of the column, the progressive damage and failure model available in ABAQUS/Explicit were utilized in the present numerical model. According to this model, the onset of shear damage is characterized by the value equivalent to plastic strain at the initiation of shear damage $\varepsilon_{S}^{\mathrm{pl}}$. The value of this strain was input in the present model as a tabular function of the strain rate and shear stress ratio [13]. Material degradation is started and local shear damage is initiated when the following equation is valid:

$$
\Phi_{S}=\frac{\sum \Delta \varepsilon^{\mathrm{pl}}}{\varepsilon_{S}^{\mathrm{pl}}}=1
$$

where $\Phi_{S}$ is the shear damage initiation criterion and $\sum \Delta \mathcal{E}^{\mathrm{pl}}$ is the value of the accumulative equivalent plastic strain at integration points. In the present numerical model, the fracture strain at damage initiation was first assumed to be 0.15 from the stress versus plastic strain relationship of the steel material. Subsequently, a numerical simulation was carried out for the steel column under same blast loads but using classical metal plasticity constitutive model to obtain values of shear stress ratio and strain rate at damage initiation. Table 2 shows values of material failure quantities used in the present numerical model. The shear failure of steel column occurs when shear damage initiation has been detected from (1) at any location of the steel column.

2.2. Sequence of Load Application. The suggested numerical model is mainly intended to simulate the behaviour of a steel column subjected to blast load with a considerable value of static axial compressive load. Hence, the model must be able to maintain a static axial load on the column while it is subjected to the blast event. This means that both the static and dynamic loads should be exerted simultaneously during the entire dynamic analysis duration. In ABAQUS/Explicit, only dynamic analysis is allowed. Therefore, the static axial load must be applied as a quasi-static load using the quasistatic analysis in ABAQUS/Explicit. To perform a quasistatic analysis in the present study, the load was applied as a time-dependent variable using the SMOOTH AMPLITUDE suboption [12]. Furthermore, the time period during which the axial load is applied was selected to be 0.012 seconds for the steel section W150 $\times 24$ and 0.14 seconds for the steel section $\mathrm{W} 200 \times 71$. These time durations represent lower natural periods of the structural system in order to produce accurate static results by mitigating the pseudodynamic effects [15, 17].

The blast load was generated in the experimental test by a direct real explosion using different explosive charges [4]. The pressure-time history and the total impulse for each charge were recorded using pressure transducers which were installed at different locations on the test setup. In the present numerical model, the pressure-time history for each case was simulated as a load-time function using the AMPLITUDE option in ABAQUS [12] as shown in Figure 3. Figure 3 shows that only the positive phase of the pressure-time history was used in the numerical analysis because, in most cases, maximum deformation and failure of structural members occurred during this phase of the blast pressure-time history.

2.3. Simulation Results. The results obtained from numerical simulations were compared with the corresponding recorded experimental test results in terms of permanent deflection shape and normal strain history for the two test cases considered in the validation, namely, $4 \mathrm{C} 1$ and $5 \mathrm{C} 1$, as shown 


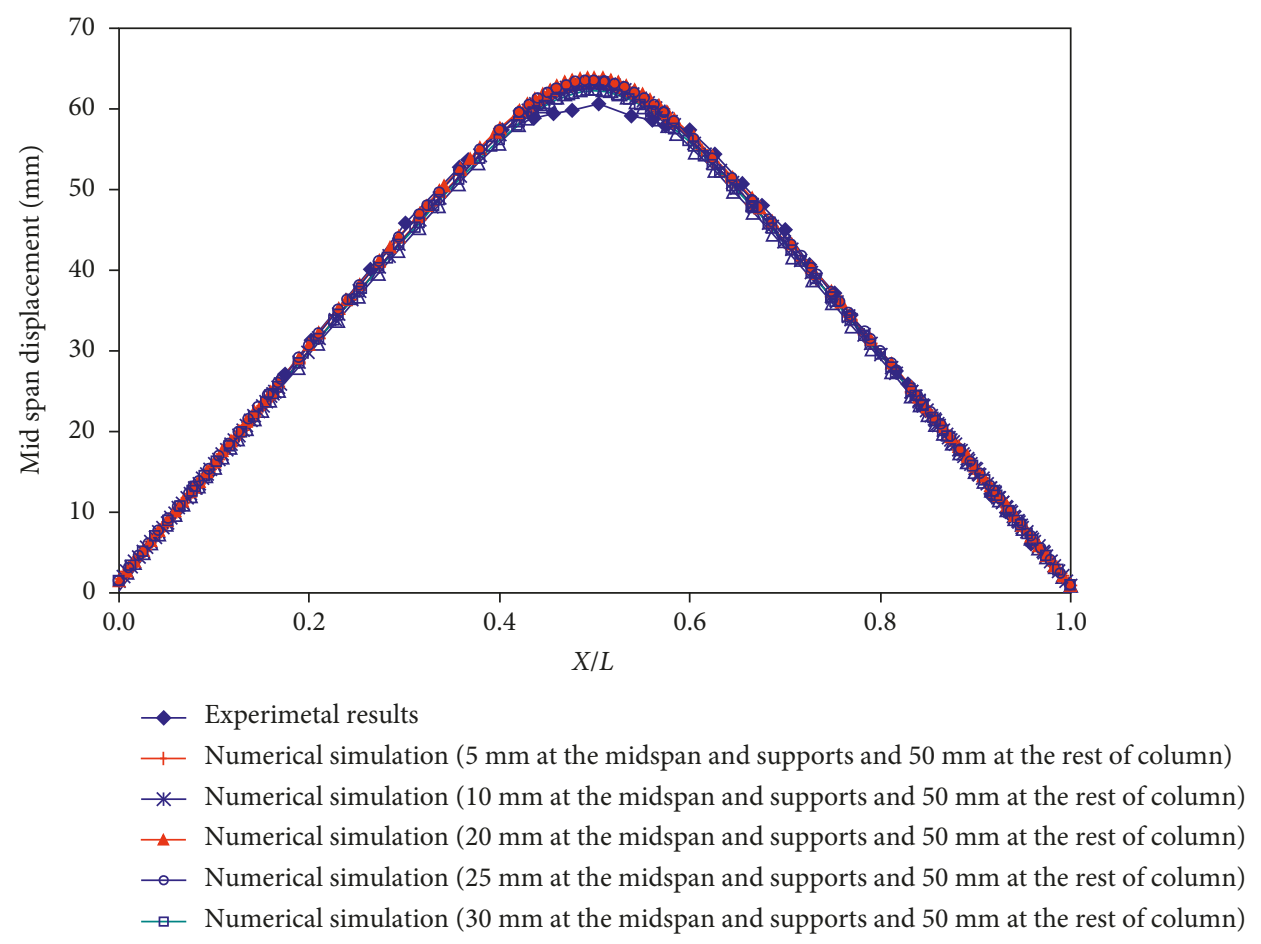

Figure 2: Comparison of the permanent deflected shape of the steel column 4C1 between the experimental test of Nassr et al. [4] and the present numerical simulation using different mesh sizes.

TABLE 2: Failure parameters used in the present model.

\begin{tabular}{lcc}
\hline $\begin{array}{l}\text { Fracture } \\
\text { strain }\end{array}$ & $\begin{array}{c}\text { Maximum shear } \\
\text { stress ratio }\end{array}$ & $\begin{array}{c}\text { Maximum strain } \\
\text { rate }\left(\mathrm{sec}^{-1}\right)\end{array}$ \\
\hline 0.15 & 1.8 & 16.7 \\
\hline
\end{tabular}

in Figures 2, 4, and 5. Figures 2 and 4 compare the deflected shapes of the columns after blast test. Excellent correlation can be seen between the two sets of results. According to the experimental tests of Nassr et al. [4], none of the tested columns had experienced global or local failures, and the presented numerical model has successfully simulated the same behaviour.

To investigate the sensitivity of the simulation results to the mesh size selected to model the steel columns, simulations were carried out using five different sizes of mesh used at zones where high stress concentrations were excepted to develop (i.e., at the column midspan and at the column ends) as shown in Figure 1. Figure 2 shows good agreement between the results obtained using different mesh sizes. However, the mesh size of $20 \mathrm{~mm}$ at the column midspan and the column ends and $50 \mathrm{~mm}$ for the rest of the column gives the best agreement with the experimental test results. Therefore, this combination of meshes will be used throughout this study.

Figures 5(a) and 5(b) show good correlation of the strain time histories at the middle of the tension flange of the column midspan between the recorded and the predicted results. This agreement indicates the ability of the suggested model to capture the changes in strains and stresses during the very short time duration of the blast event; hence, it can be used to capture the failure that occurred during this short time period.

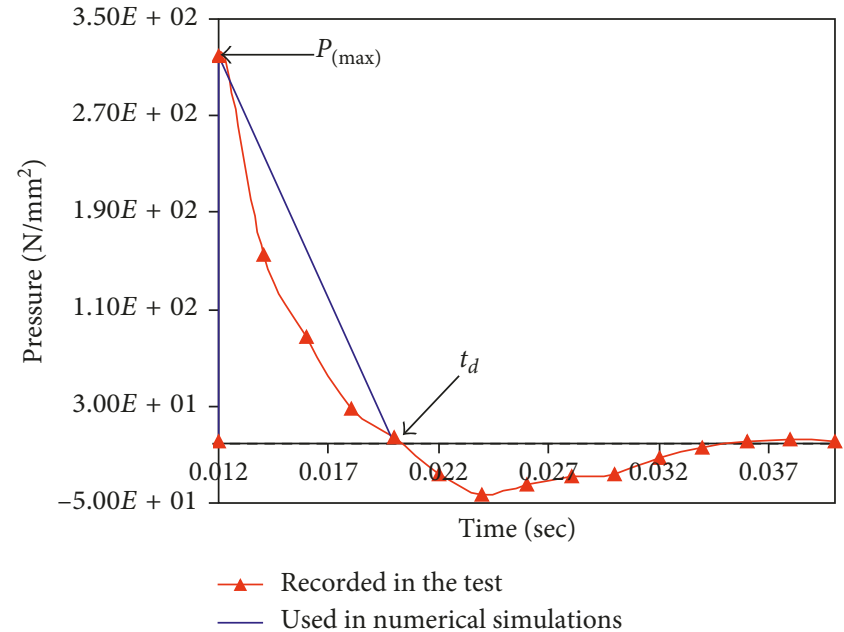

FIgURE 3: Comparison between the recorded [4] and simulated pressure-time history of the blast load.

Finally, Figure 6 shows the damage criterion along the middle of the tension flange of the two steel columns used in the validation. The maximum values of the damage criterion were predicted at the location of the high stress concentration as shown in the figure (i.e., at the midspan and at the fixed support). However, no damage occurred at these points because the value of this damage criterion was still below the damage initiation limit (i.e., one).

The above validation results indicate that the present numerical model is capable of predicting the response and failure of steel columns under blast loads. 


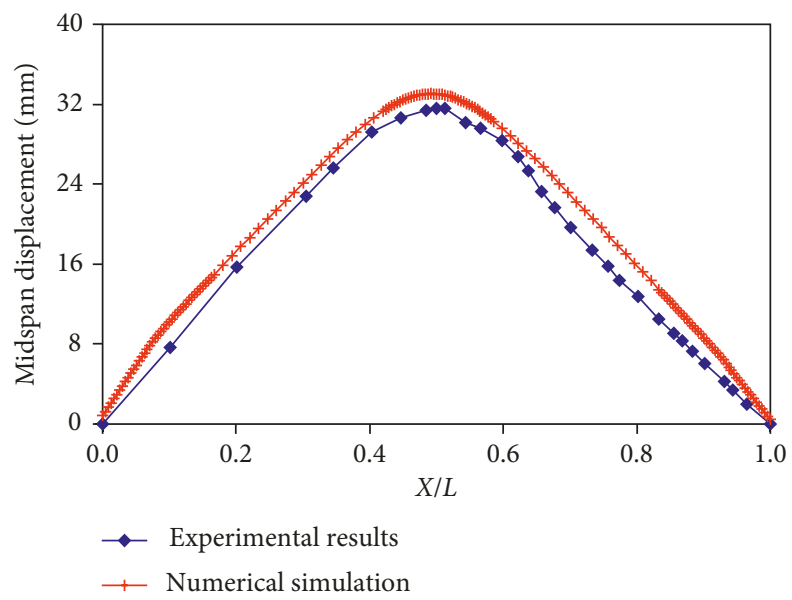

FIgURE 4: Comparison of the permanent deflected shape of the steel column 5C1 between the experimental test of Nassr et al. [4] and the present numerical simulation.

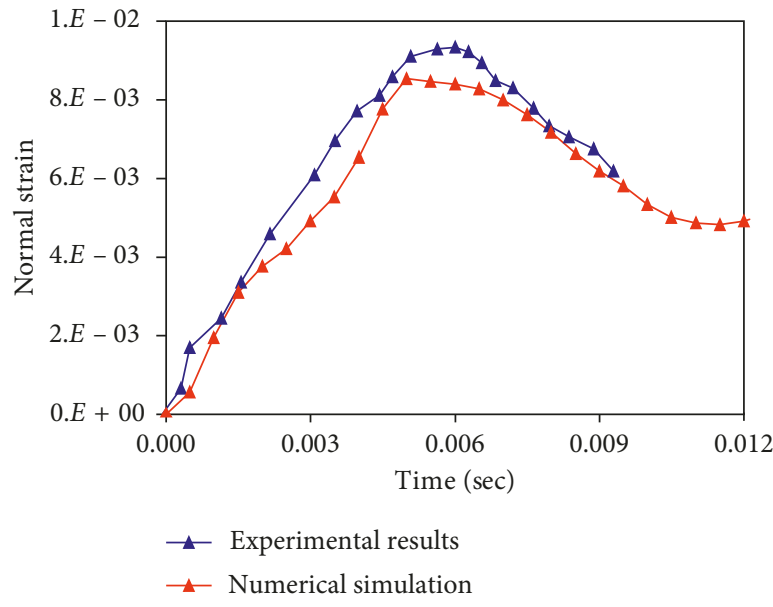

(a)

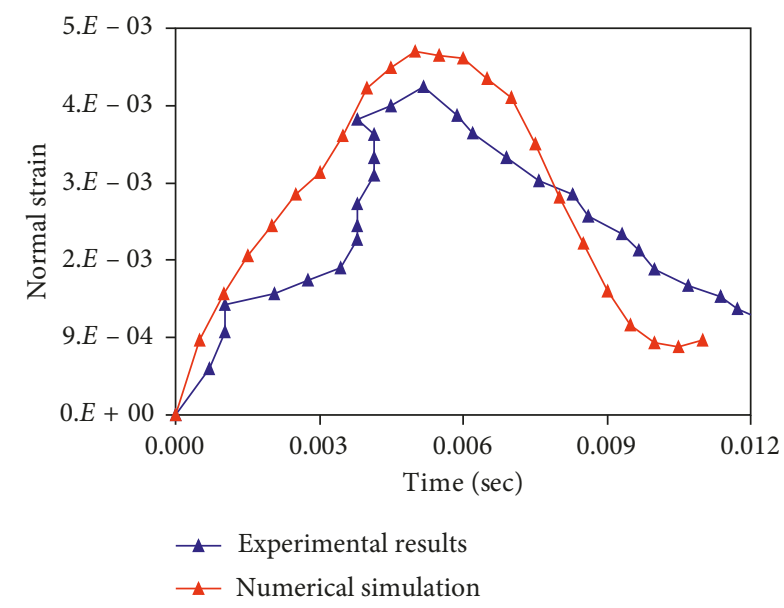

(b)

FIGURE 5: Comparison of the strain time histories of the steel columns 4C1 (a) and 5C1 (b) between the experimental tests of Nassr et al. [4] and the present numerical simulation.

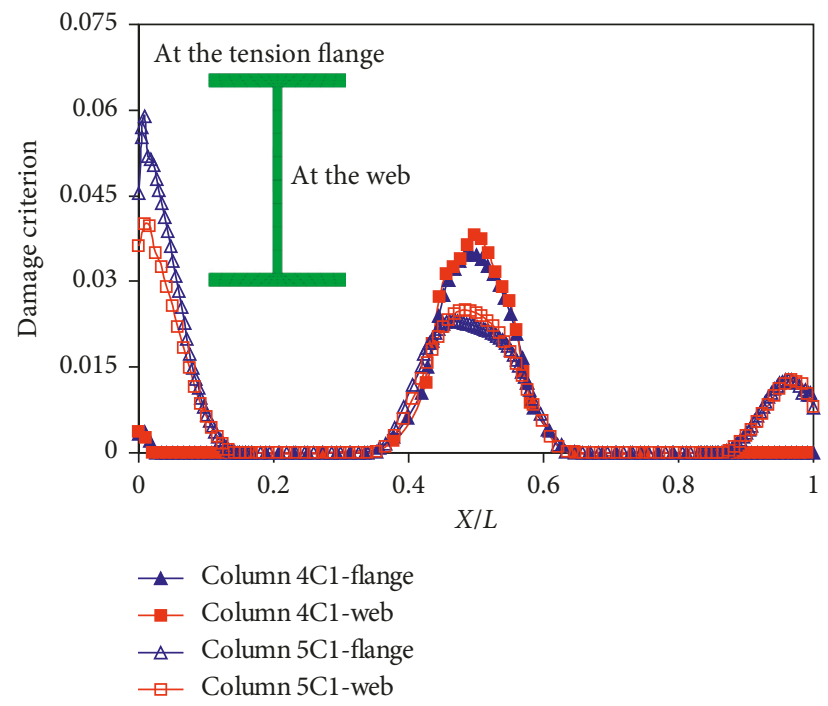

FIGURE 6: Numerical prediction of the damage initiation criterion along the tension flange and the web of steel columns 4C1 and 5C1 used in Nassr et al.'s tests [4]. 
TABLE 3: The parameters used in the parametric study.

\begin{tabular}{|c|c|c|c|c|}
\hline Section & Axial load ratio & Boundary conditions & Blast direction & Slenderness ratio $(k L / r)$ \\
\hline \multirow{2}{*}{$\mathrm{W} 150 \times 24$} & \multirow{2}{*}{$0.25,0.5,0.75$} & Rolled-pinned & $x-x, y-y$ & $\left(\frac{k L}{r}\right)_{x-x}=45.5,\left(\frac{k L}{r}\right)_{y-y}=122$ \\
\hline & & Rolled-fixed & $x-x, y-y$ & $\left(\frac{k L}{r}\right)_{x-x}=31.85,\left(\frac{k L}{r}\right)_{y-y}=85.4$ \\
\hline \multirow{2}{*}{$\mathrm{W} 200 \times 71$} & \multirow{2}{*}{$0.25,0.5,0.75$} & Rolled-pinned & $x-x, y-y$ & $\left(\frac{k L}{r}\right)_{x-x}=32.7,\left(\frac{k L}{r}\right)_{y-y}=56.78$ \\
\hline & & Rolled-fixed & $x-x, y-y$ & $\left(\frac{k L}{r}\right)_{x-x}=22.9,\left(\frac{k L}{r}\right)_{y-y}=39.75$ \\
\hline
\end{tabular}

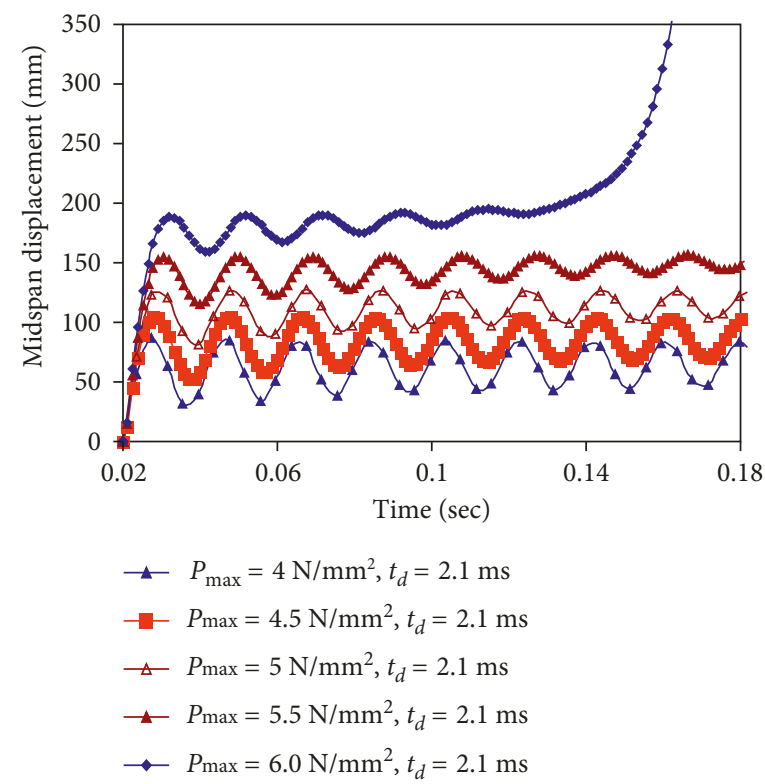

Figure 7: Midspan lateral displacement time histories of the steel column W150 $\times 24$ subjected to different values of blast impulse.

\section{Parametric Study}

This section investigates the effects of important parameters on the behaviour and failure modes of axially and statically preloaded steel column subjected to blast load through an extensive parametric study. The conclusions extracted from this parametric study may be used to suggest assumptions that could enable simple and practical methods of analysis to be developed. These parameters have been identified to be blast impulse, blast energy, axial compressive load, column slenderness ratio, column boundary condition, and the blast direction.

3.1. The Selected Parameters. The parametric study used the same steel columns' sections selected in the validation exercises with same material properties. However, the columns' lengths were increased to $3 \mathrm{~m}$ since this length is more common in practical application. The direction of blast pressure was to cause bending about both the major $(x-x)$ and the minor $(y-y)$ directions of the column to account for the effect of slenderness ratio and local buckling on the columns' response and failure. For each direction of bending, two cases of boundary conditions were considered: the simply supported and the propped cantilever conditions.
The axial compressive load was applied in three different values calculated as percentages of the column design axial static load determined according to AISC specifications [16]. The same numerical model that was employed in the previous section was used in the parametric study with same mesh size, material behaviour, and loading sequence. However, the yield stress was taken here to be $440 \mathrm{~N} / \mathrm{mm}^{2}$. Table 3 lists all the parameters used.

\subsection{Analysis of Results}

3.2.1. Blast Impulse and Blast Energy. Numerical simulations were first carried out on a simply supported W150 $\times 24$ section column subjected to increasing levels of the blast impulse to cause column failure under $50 \%$ of the column design axial static load. The direction of blast pressure was selected to cause bending about the column strong axis. Column failure was detected either by column global buckling which is identified by large deformation or by local damage and failure which is identified by the value of the damage initiation criterion. Figure 7 shows the load deformation relationships of the steel columns under different levels of blast pressure. It can be seen from this figure that, at the value of blast 


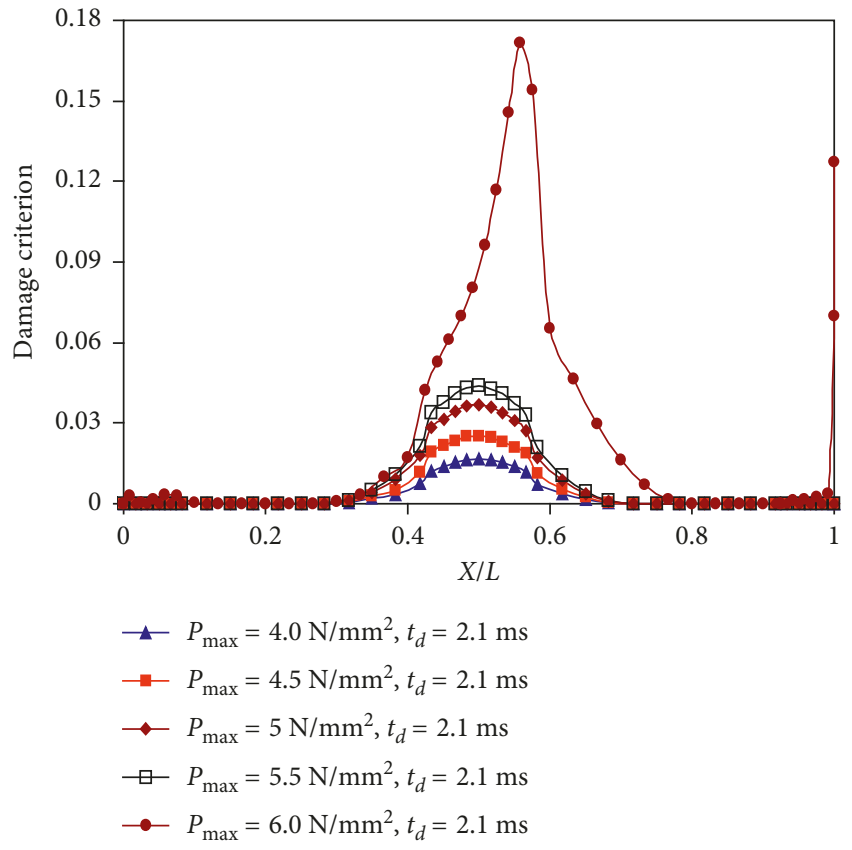

(a)

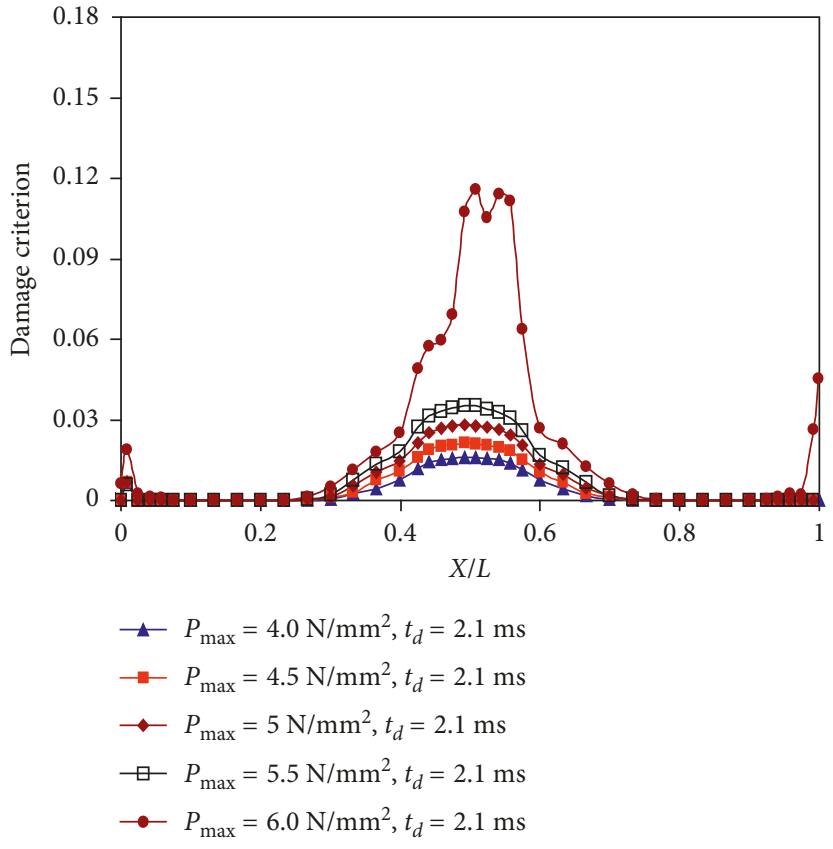

(b)

FIGURE 8: Damage initiation criterion profile along the steel column W150 $\times 24$ subjected to different values of the blast impulse: (a) at the middle of the tension flange; (b) at the middle of the web.

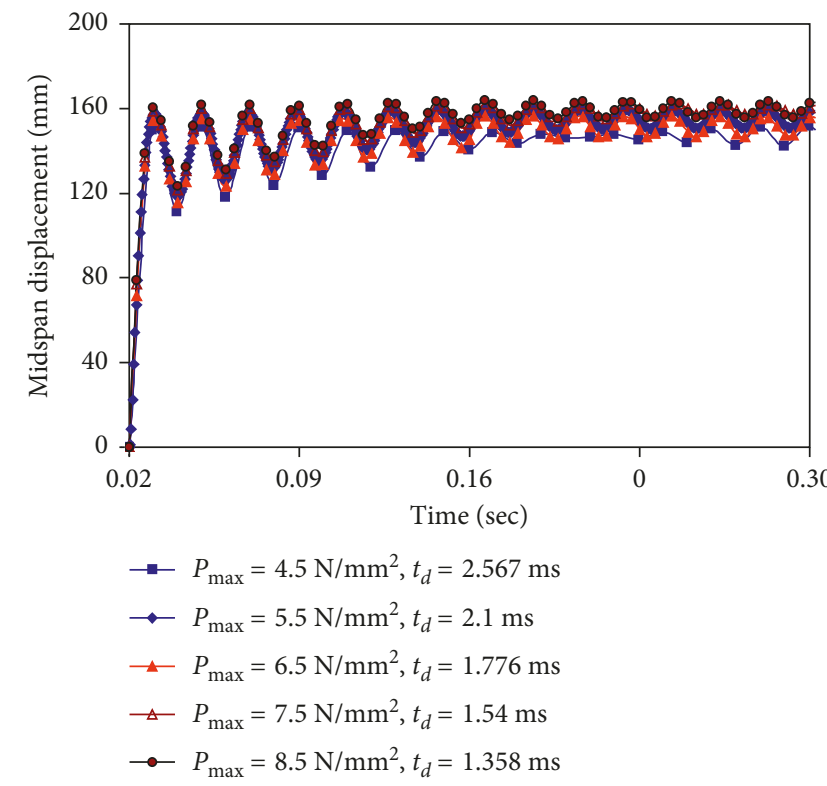

(a)

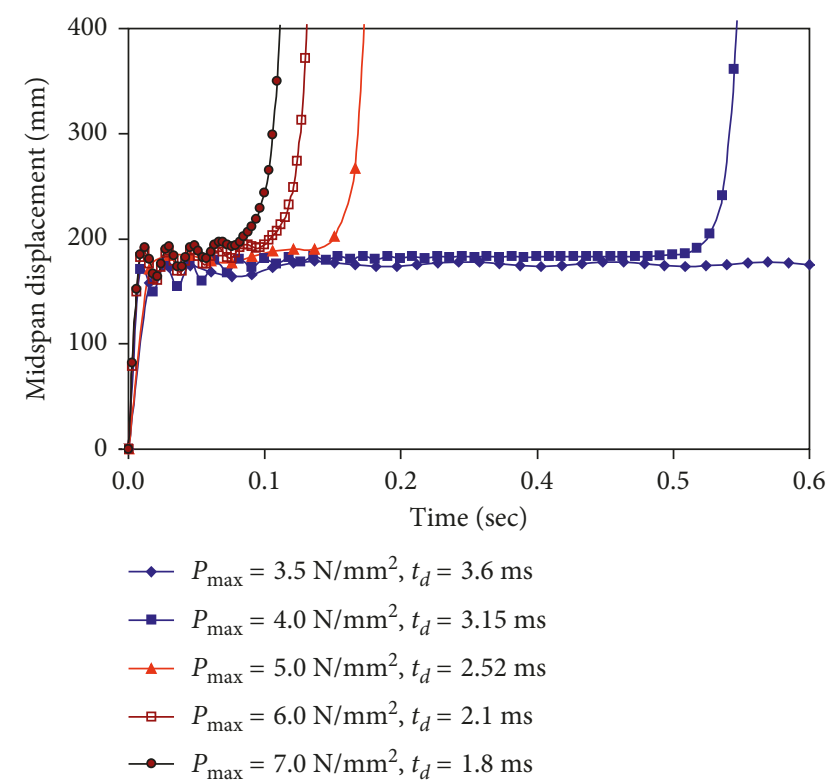

(b)

Figure 9: Midspan lateral displacement time histories of the steel column W150 $\times 24$ subjected to constant values of blast impulses with different combinations of blast parameters.

impulse of $0.0063 \mathrm{~N} / \mathrm{mm}^{2} \cdot \sec$ (i.e., $P_{\max }=6 \mathrm{~N} / \mathrm{mm}^{2}$ and $t_{d}=$ $0.0021 \mathrm{sec})$, the column experienced global instability, while for other levels of blast impulse, neither global failure nor local damage were observed as shown in Figures 7 and 8 .

Now, numerical simulations were carried out using the same column but considering a constant level of the blast impulse with different combinations of blast pressure $\left(P_{\max }\right)$ and positive time duration $\left(t_{d}\right)$. Figures $9(\mathrm{a})$ and $9(\mathrm{~b})$ show the displacement time histories of the columns. It can be noticed from these figures that all columns show almost the same response under the same value of the blast impact. Figure 9(b) also indicates that under the same value of the 
TABLE 4: Equations for the kinetic energy of the column induced by the blast [9].

\begin{tabular}{lcc}
\hline Boundary condition & Kinetic energy & Equation no. \\
\hline Pinned-pinned column & $\mathrm{KE}=\frac{4 L}{\pi^{2} m} i^{2}$ & $(*)$ \\
Fixed-fixed column & $\mathrm{KE}=\frac{L}{3 m} i^{2}$ & $(* *)$ \\
Fixed-pinned column & $\mathrm{KE}=\frac{L}{2.756 m} i^{2}$ & $(* * *)$ \\
\hline
\end{tabular}

$\mathrm{KE}=$ the kinetic energy; $L=$ the column length; $m=$ the mass per unite length of the column; $i=$ the blast impulse per unite length of the column.

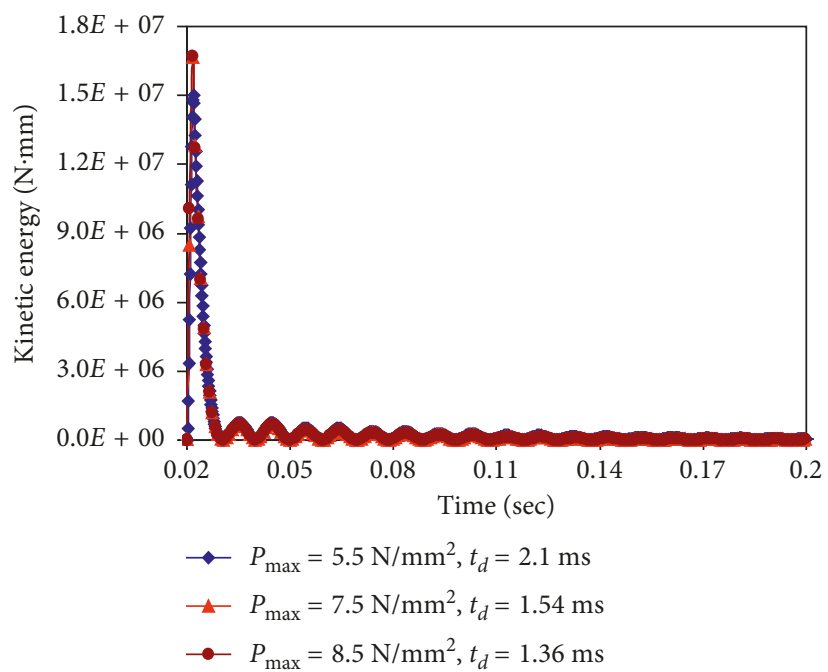

(a)

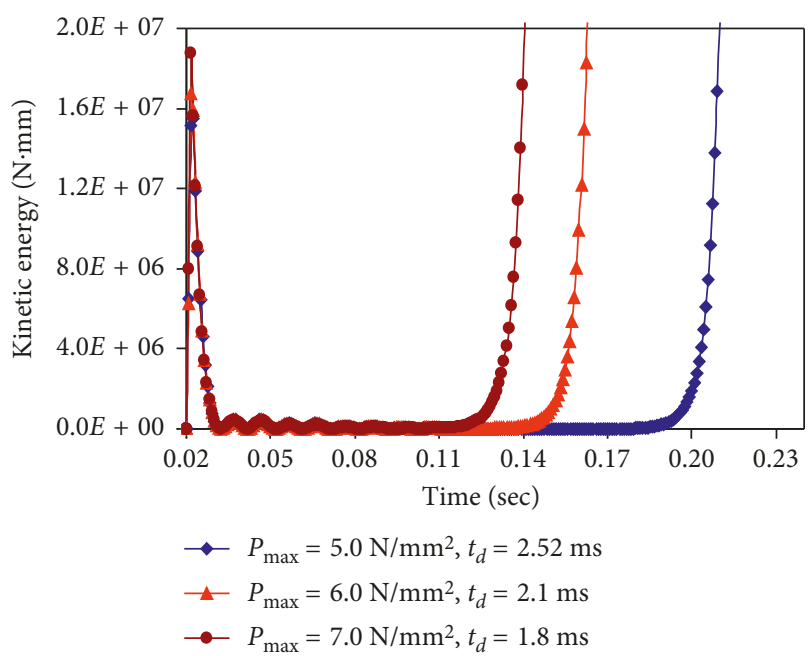

(b)

FIGURE 10: Comparison of the kinetic energy time histories of steel column W $150 \times 24$ subjected to different values of blast impulses under $50 \%$ of the design axial load: (a) without column failure; (b) with column failure.

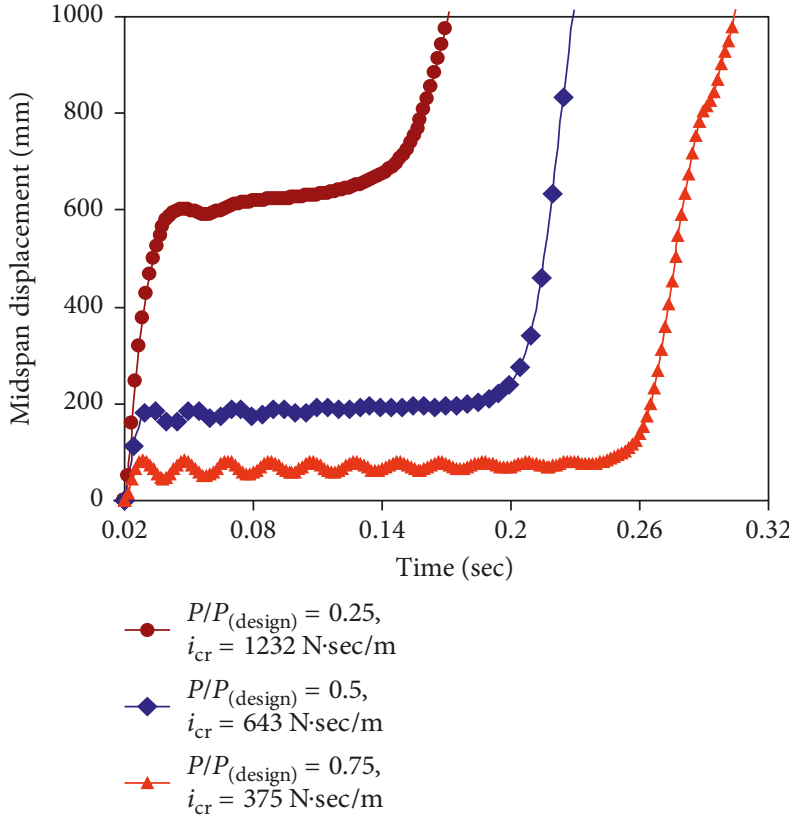

(a)

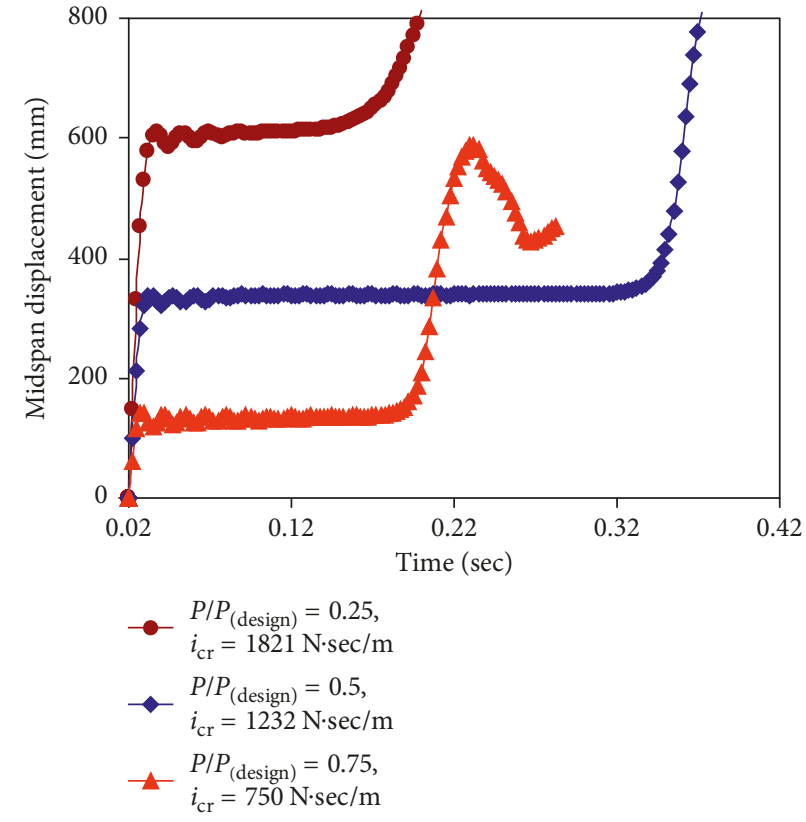

(b)

Figure 11: Midspan displacement time histories of steel column W150 $\times 24$ with bending about the major $x$ - $x$ axis. (a) Simply supported. (b) Propped cantilever. 


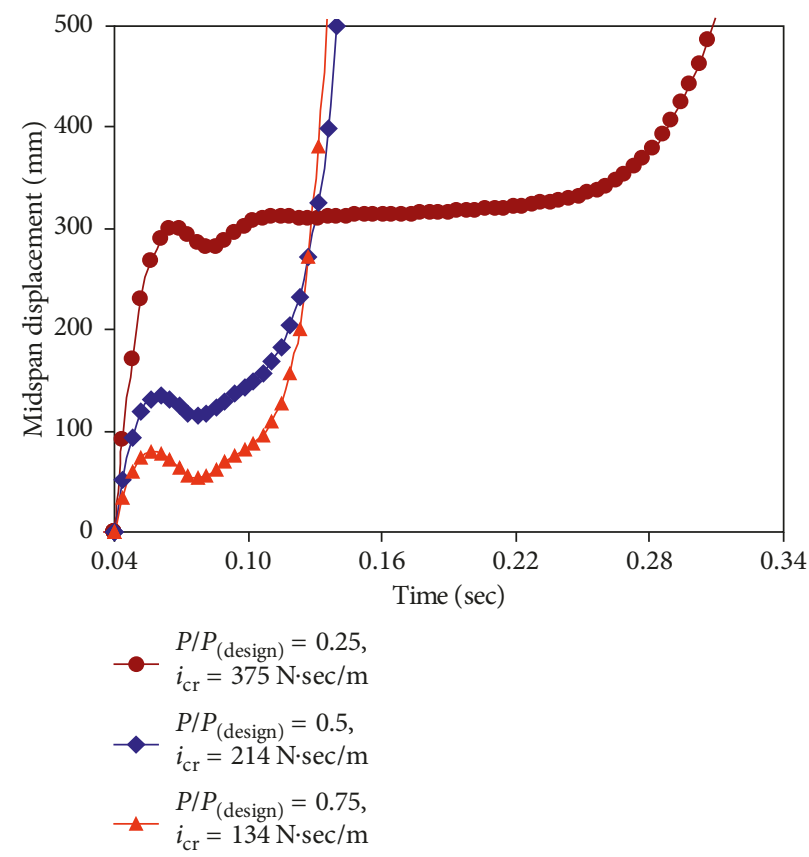

FIGURE 12: Midspan displacement time histories of the propped cantilever column $\mathrm{W} 150 \times 24$ with bending about the minor $y$ - $y$ axis.

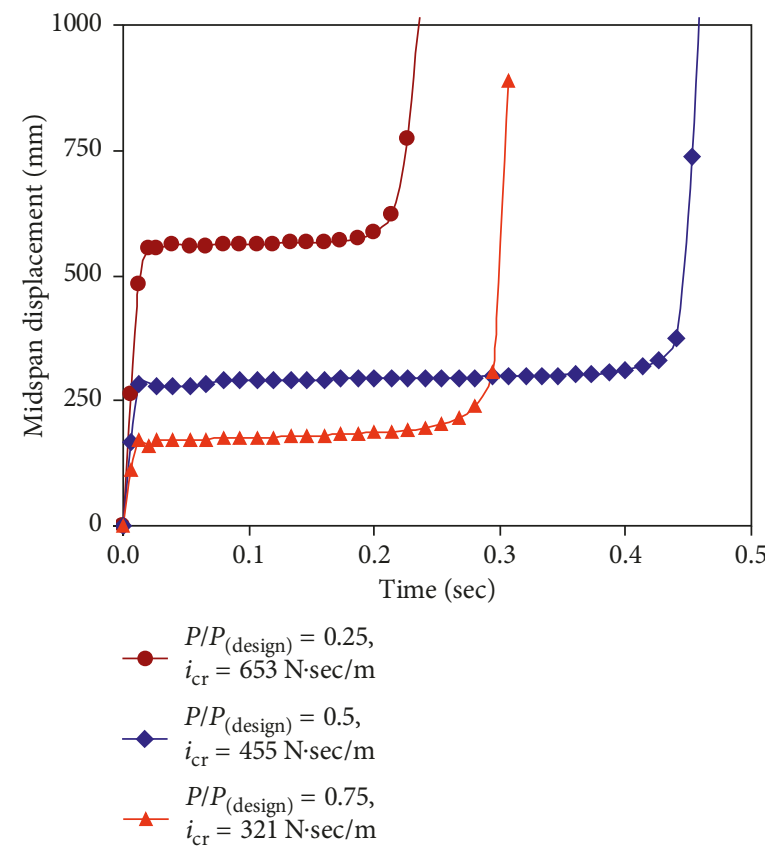

(a)

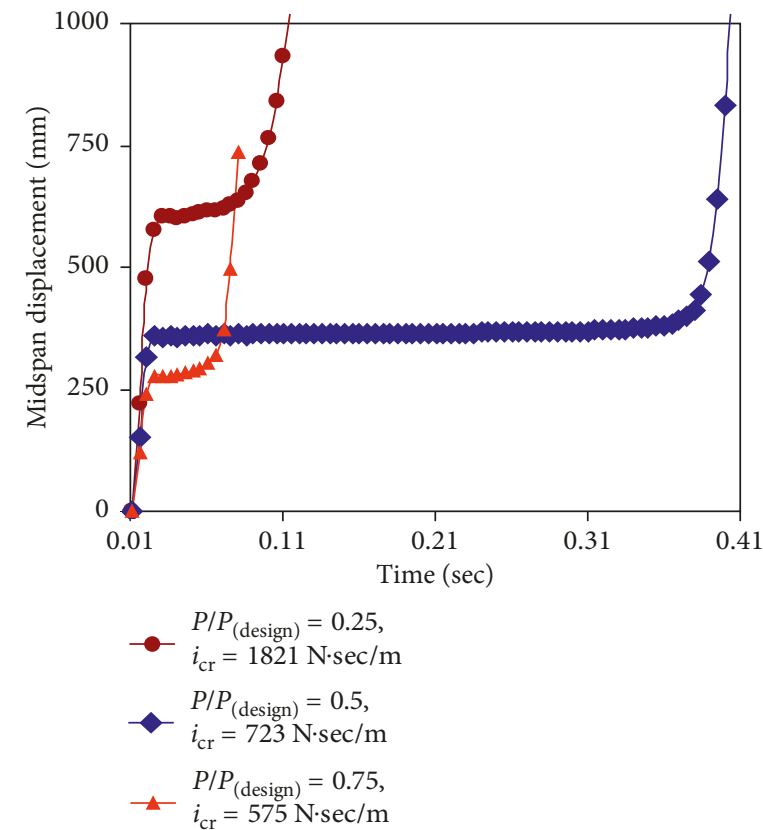

(b)

FiguRE 13: Midspan displacement time histories of steel column W200 $\times 71$ with bending about the major $x$ - $x$ axis. (a) Simply supported. (b) Propped cantilever.

blast impulse, when the blast pressure is decreased, the time required to cause column failure was increased, and when the value of the blast pressure was very low, the column did not experience any failure. This behaviour can be attributed to the quasi-static effect of the applied blast pressure. When the blast pressure is low, longer time duration would be needed to produce the same impulse value. When blast wave time duration is larger than a tenth of the first natural time period of the column ( $t=0.018$ seconds in this case), the column behaves in a quasi-static manner [17]. In this situation, the maximum blast pressure dominates the column response and failure rather than the blast impulse [9]. Hence, 


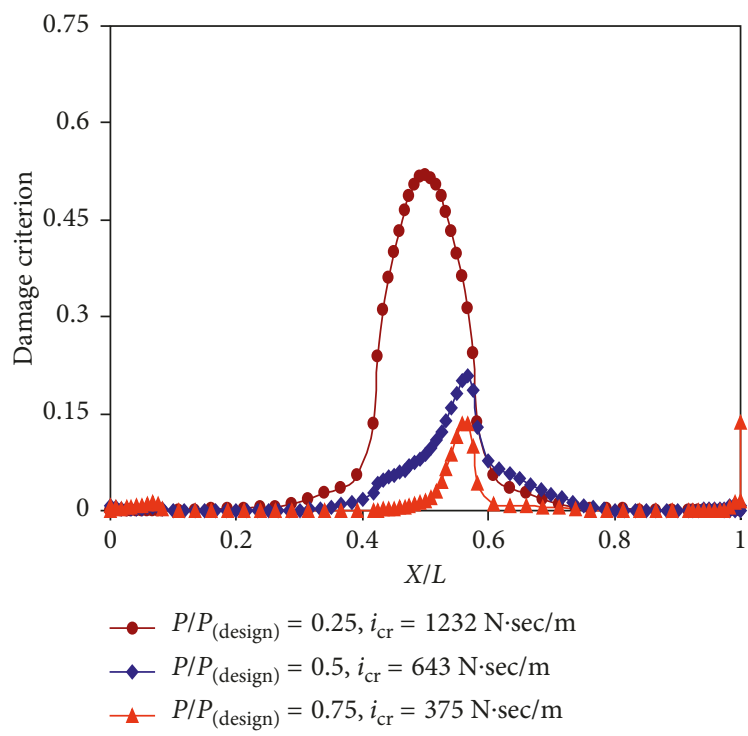

(a)

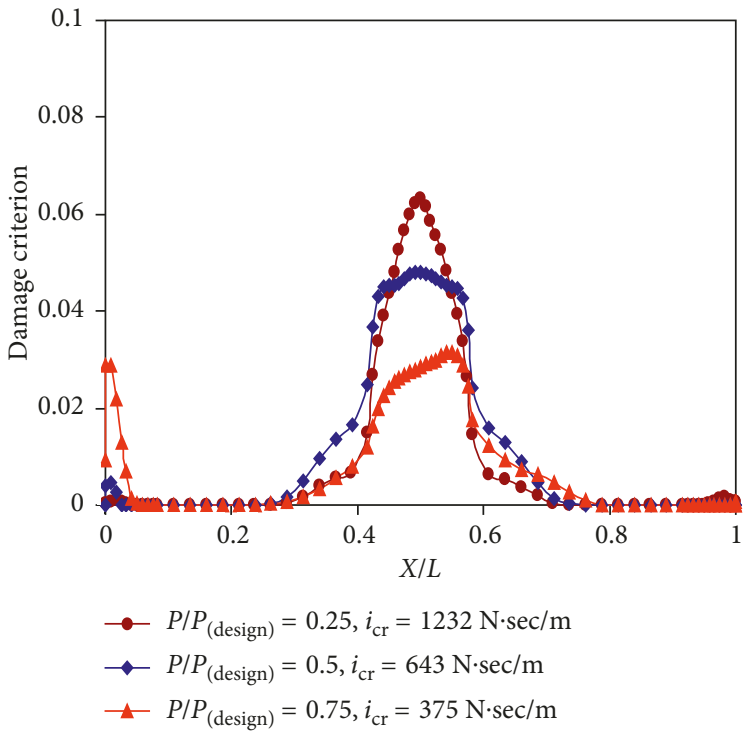

(b)

FIGURE 14: Damage initiation criterion profile of simply supported column W150 $\times 24$ with bending about major $x$ - $x$ axis: (a) at the middle of the tension flange; (b) at the middle of the web.

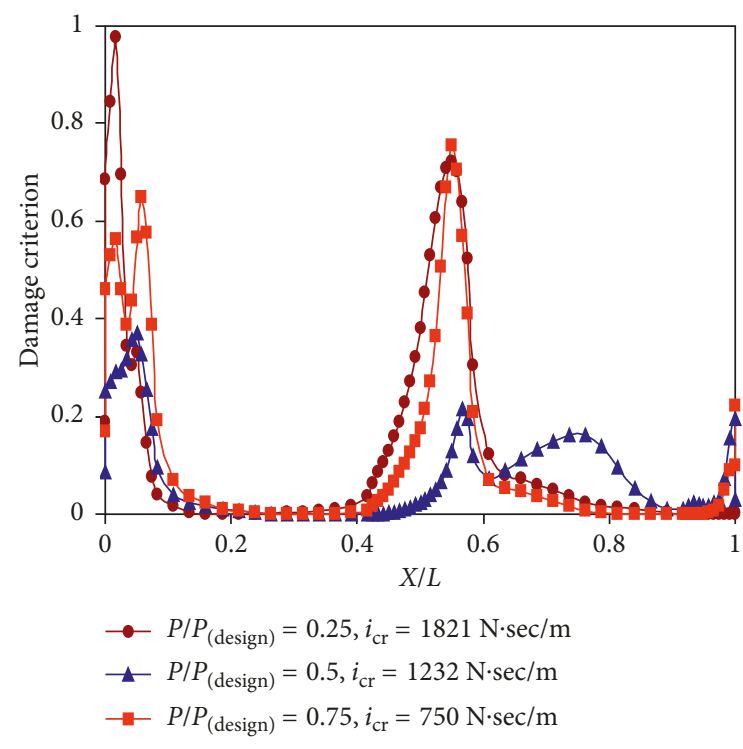

(a)

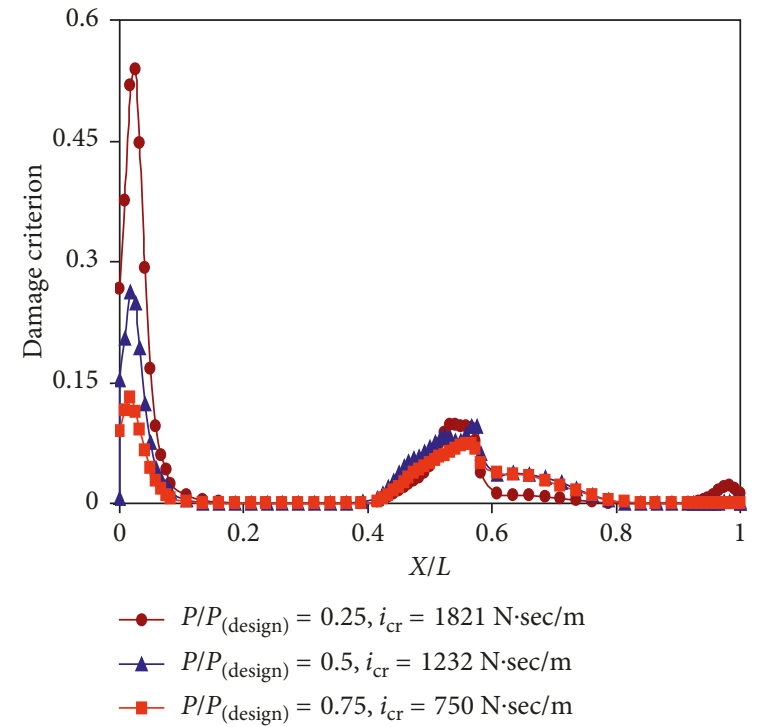

(b)

FIGURE 15: Damage initiation criterion profile of propped cantilever column W150 $\times 24$ with bending about major $x$ - $x$ axis: (a) at the middle of the tension flange; (b) at the middle of the web.

a very low value of blast pressure would not be able to cause column failure.

The kinetic energy of the steel column imparted from the blast can be related to the total blast impulse as expressed by the equations in Table 4 [9]. Hence, if the column response and failure depend solely on the value of the blast impulse as demonstrated by Figures 7 and 8, the kinetic energy imparted to the column may also control the column failure and could be used to establish the failure criterion of the column. The initial kinetic energy induced by the blast pressure reaches maximum value just after the application of the blast load. Subsequently, the residual kinetic energy decreases when the strain energy of the column absorbs the blast energy, and the column comes to rest when the residual kinetic energy is equal to zero $\left(\mathrm{KE}_{\text {(residual) }}=0\right)$ and maintains this value, if no failure occurs (Figure 10(a)). However, if the column has failed due to global instability, the column deformation increases abruptly, and the kinetic energy increases again as shown in Figure 10(b). 


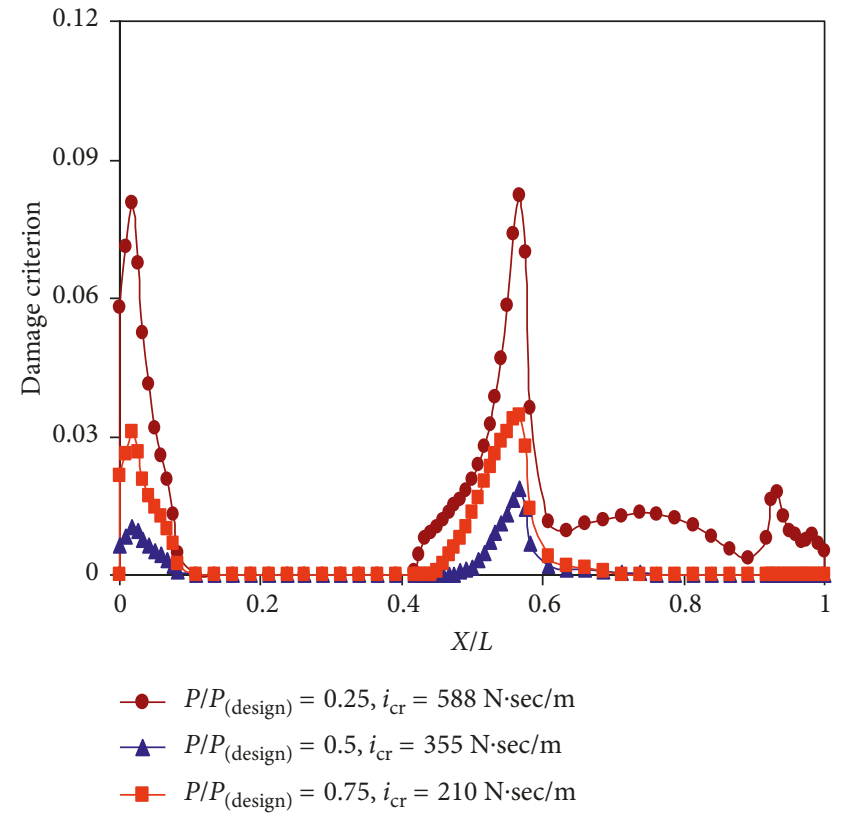

(a)

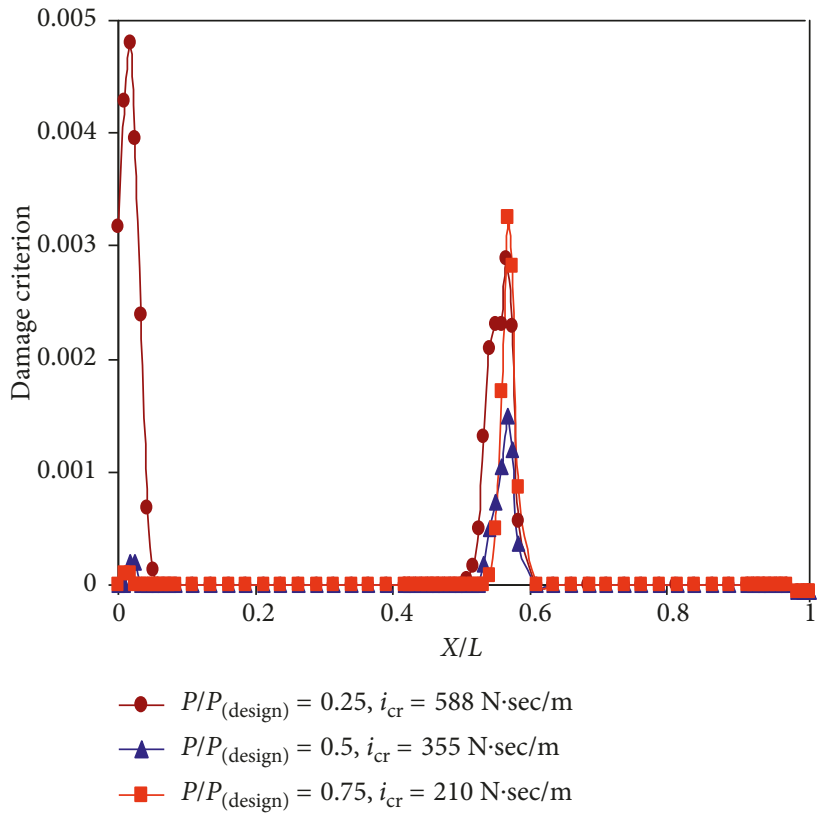

(b)

FIGURE 16: Damage initiation criterion profile of propped cantilever column W $150 \times 24$ with bending about minor $y$ - $y$ axis: (a) at the middle of the tension flange; (b) at the middle of the web.

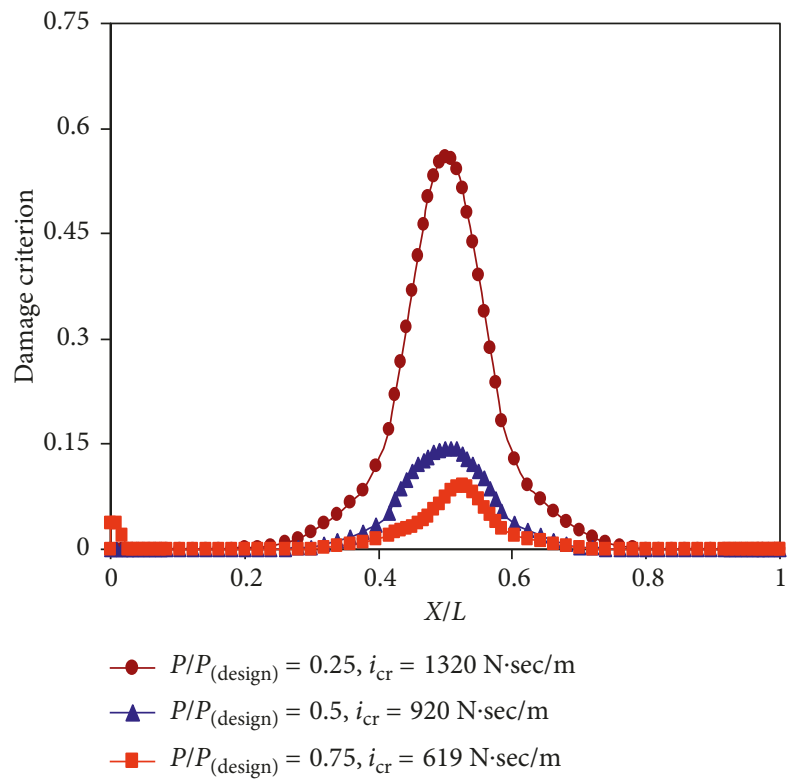

(a)

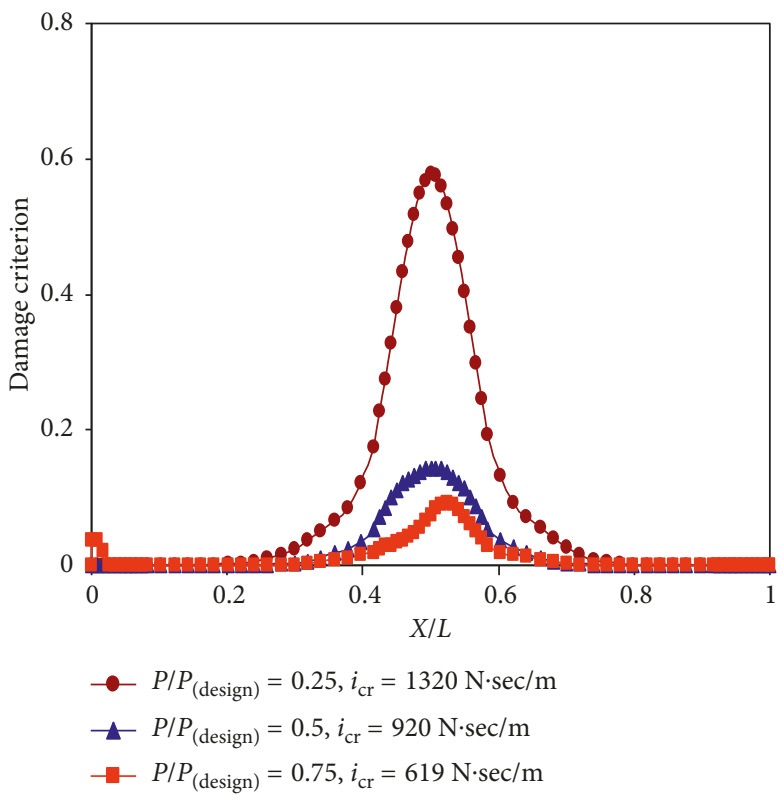

(b)

FIGURE 17: Damage initiation criterion profile of simply supported column W200 $\times 71$ with bending about major $x$ - $x$ axis: (a) at the middle of the tension flange; (b) at the middle of the web.

3.2.2. Failure Modes. In this section, the steel columns listed in Table 1 were subjected to three different levels of axial compressive load (Table 2). For each axial load level, the applied dynamic impulse was gradually increased until the columns experienced local failure indicated by the value of the damage initiation criterion or global failure indicated by the large deformation and instability of the columns; Figures 11-19 show the simulation results. As can be seen from columns' midspan displacement time histories shown in Figures 11-13, most of the columns experienced global failure. To investigate whether the blast load caused local damage and failure in the columns before global failure, 


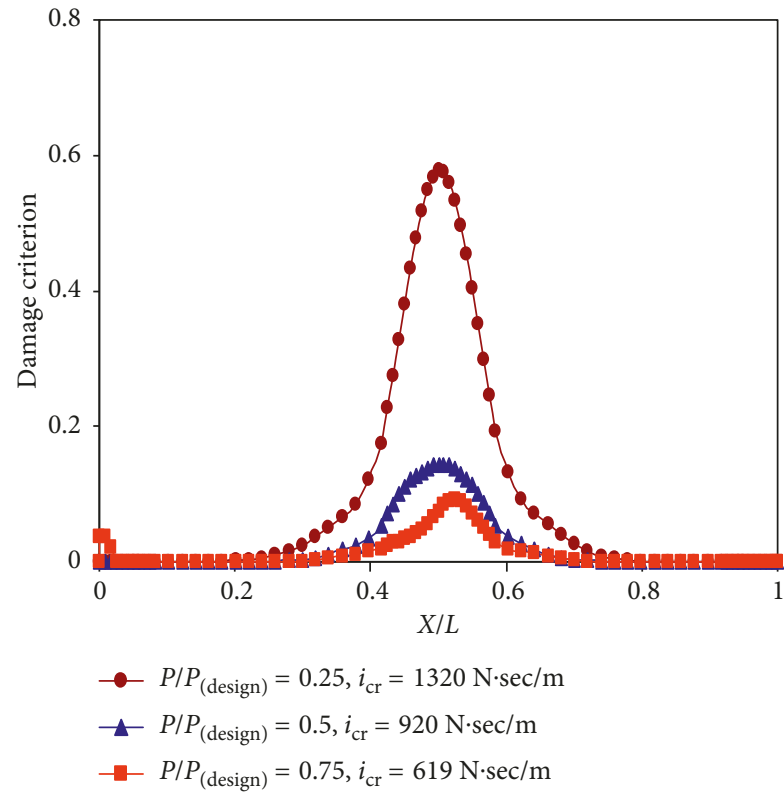

(a)

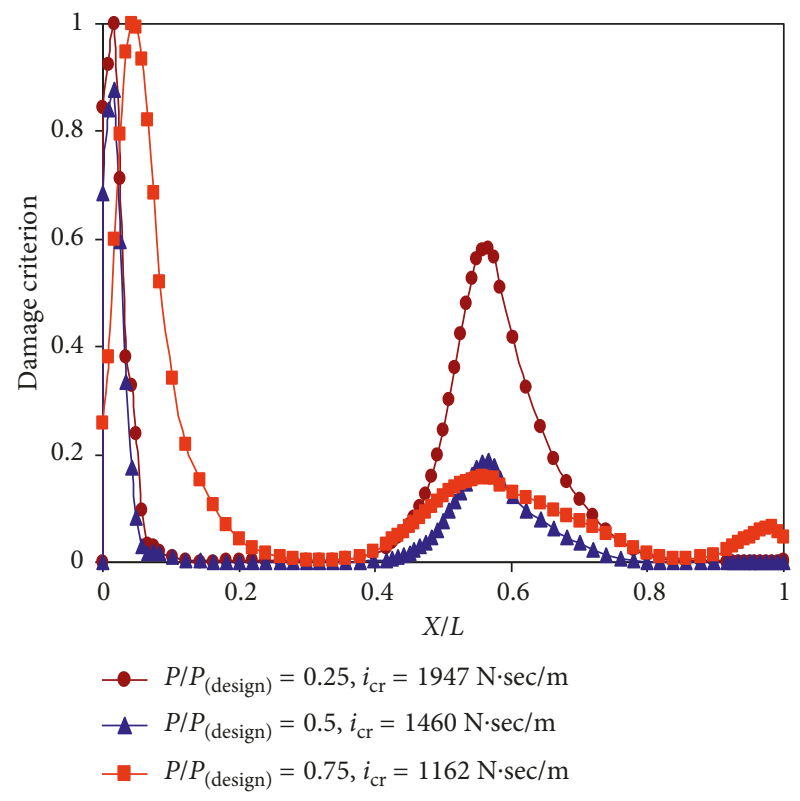

(b)

FIGURE 18: Damage initiation criterion profile of propped cantilever column W200 $\times 71$ with bending about major $x$ - $x$ axis: (a) at the middle of the tension flange; (b) at the middle of the web..

Figures 14-18 show the damage initiation profile along the columns' length at the middle of the tension flange (where maximum tensile stresses are predicted) and at the middle of the web (where maximum shearing stress is predicted). These values were captured at the time just before the columns have lost their global stability. Figures 14-17 clearly show that the damage criterion values are below the failure limit' and no local failure occurred before the columns' global failure.

Figures 14-18 also show that the maximum values of the damage initiation criterion have been predicted at the fixed support when the axial load ratio is 0.25 . The damage initiation criterion approaches the damage limit at the tension flange (i.e., 1.0) in Figures 15(a) and 18(a), indicating that the columns are more prone to local shear failure at the column base under such conditions. Moreover, it can be seen from Figures 18(b) and 19 that shear damage failure has occurred at the web in column $\mathrm{W} 200 \times 71$ at the location of the fixed support. When the slenderness ratio of the column is low as in Figures 18(b) and 19 (stocky column), it is unlikely for the column to buckle especially when the applied axial load is much smaller than the column Euler buckling load $\left(244 \times 10^{5} \mathrm{~N}\right.$ for column section $\mathrm{W} 200 \times 71$ with one end fixed). Consequently, the column would need more dynamic impulse to fail which increases the possibility of shear damage and failure near the location when high stresses occur as clearly shown in Figures 19(a) and 19(b) [10, 13].

On the other hand, Figure 19(c) shows the distribution of the damage initiation criterion over the cross sections of the steel columns shown in Figures 19(a) and 19(b). The distribution shows that the material damage was concentrated at the sections' web (only the values greater than 0.8 are presented in the figures for more clarification) indicating that shear failure is the predominate failure mode in these columns. Figure 19(c) also shows that no considerable flange bucking has been observed in the columns before the shear failure which confirms that local or shear failure is the main reason for column failure.

3.2.3. Plastic Behaviour and Local Buckling. Figures 20-23 present the deformation shapes and the locations of the yielding zones of the steel columns shown in Figures 11-13 captured at the time when the columns have just failed in the global failure mode. Also, the figures show the Von Mises stress distributions over cross sections of the columns at the plastic hinge locations. As can be seen in these figures, the columns' deformation shapes are very close to the first or natural mode shape of static buckling. On the other hand, the figures show that the yielding zones are concentrated at the fixed supports and at the locations of the maximum lateral deflection of the elastic buckling mode of the columns. These observations indicate that these columns follow the plastic mechanism collapse mode of failure [13].

According to AISC Specifications [16], the wide-flange sections W150 $\times 24$ and W200 $\times 71$ are classified as compact sections under static loading conditions because these sections can reach their full plastic moment resistance before the columns collapse in a plastic mechanism mode of failure. When the columns are subjected to dynamic loadings over very short time duration, this classification could be altered owing to increasing the value of the yield stress according to the Cowper-Symonds constitutive relationship [18]. Hence, one possible mode of failure is the local buckling at the 


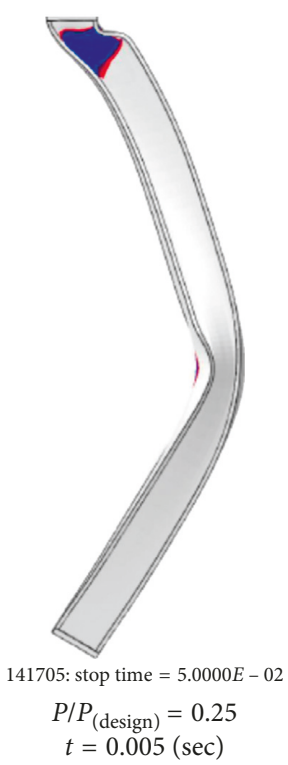

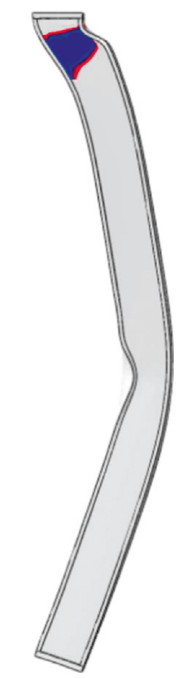

$$
\begin{gathered}
P / P_{(\text {design })}=0.5 \\
t=0.35(\mathrm{sec})
\end{gathered}
$$

(a)

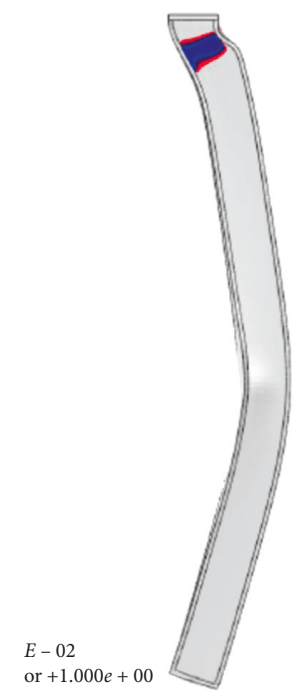

$$
\begin{gathered}
P / P_{(\text {design })}=0.75 \\
t=0.005(\mathrm{sec})
\end{gathered}
$$

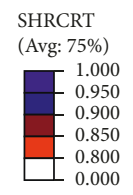

Step: blast

Increment 141705: step time $=5.0000 E-02$

Primary var: SHRCRT

Deformed var: UT deformation scale factor: $+1.000 e+00$

$$
\begin{gathered}
P / P_{(\text {design })}=0.25 \\
t=0.005(\mathrm{sec})
\end{gathered}
$$

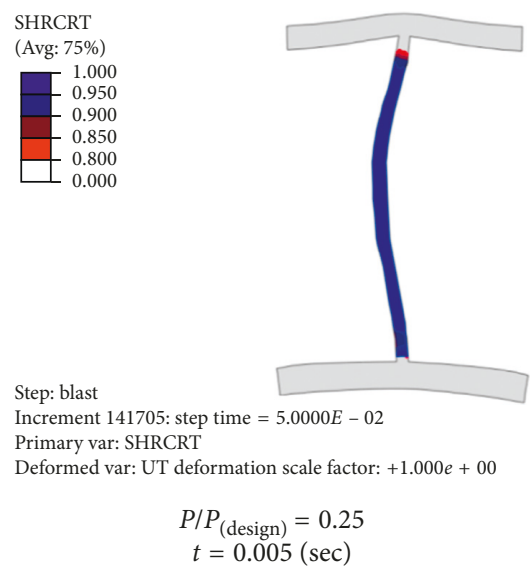

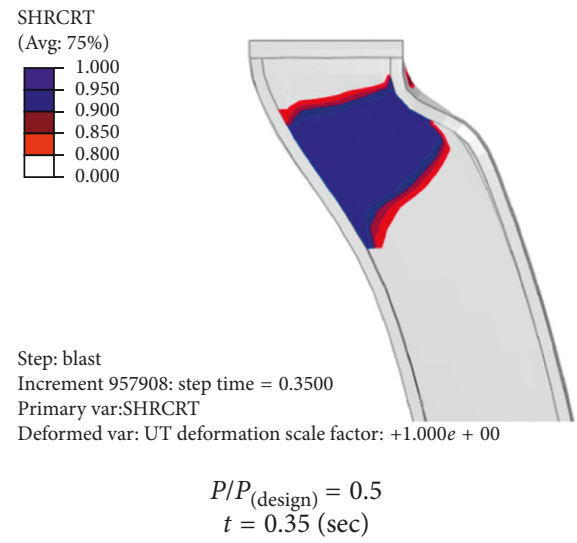

SHRCRT (Avg: $75 \%)$

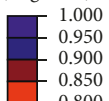

-0.900
-0.850
-0.800

$-0.800$

Step: blast

Increment 137426: step time $=5.0000 E-02$

Primary var: SHRCRT

Deformed var: UT deformation scale factor: $+1.000 e+00$

$t=0.35$ (sec)

$$
\begin{gathered}
P / P_{(\text {design })}=0.75 \\
t=0.005(\mathrm{sec})
\end{gathered}
$$

(b)
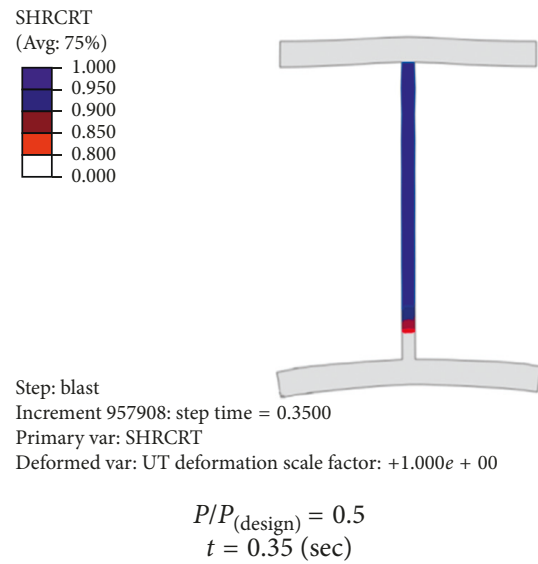

Step: blast

Increment 137426: step time $=5.0000 E-02$

Primary var: SHRCRT

Deformed var: UT deformation scale factor: $+1.000 e+00$

$$
\begin{gathered}
P / P_{(\text {design })}=0.75 \\
t=0.005(\mathrm{sec})
\end{gathered}
$$

(c)

Figure 19: (a) Deformation shape and damage initiation criterion distribution along the column length for the propped cantilever column W200 $\times 71$ with bending about major $x$ - $x$ axis. (b) A close-up view of the column at the fixed support showing. (c) A cross-sectional view of the columns at the fixed supports. 


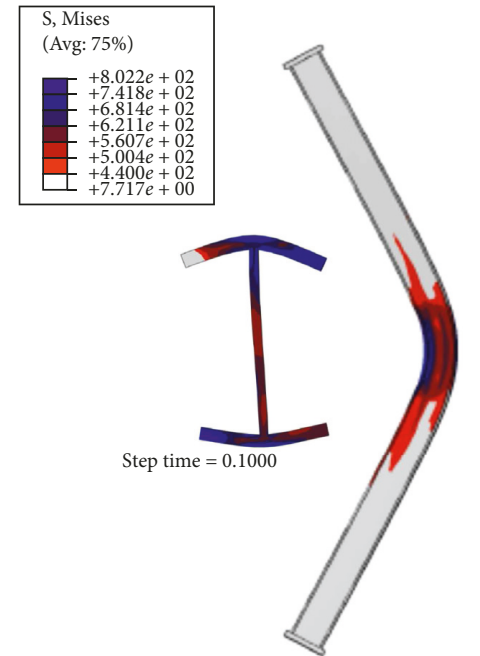

Step time $=0.1000$

$P / P_{(\text {design })}=0.25$

$t=0.1(\mathrm{sec})$

(a)

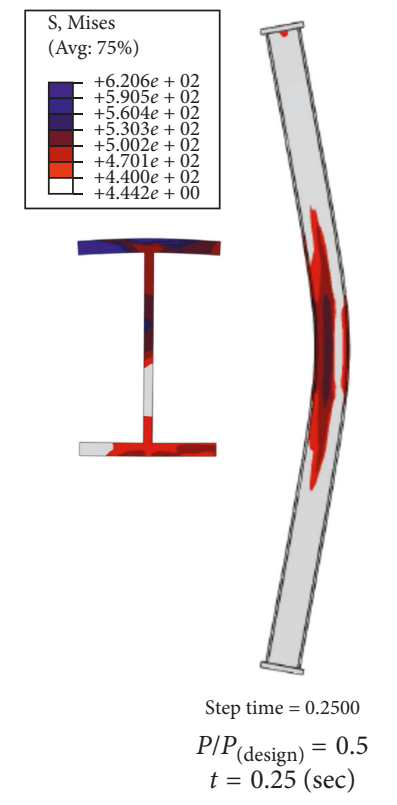

(b)

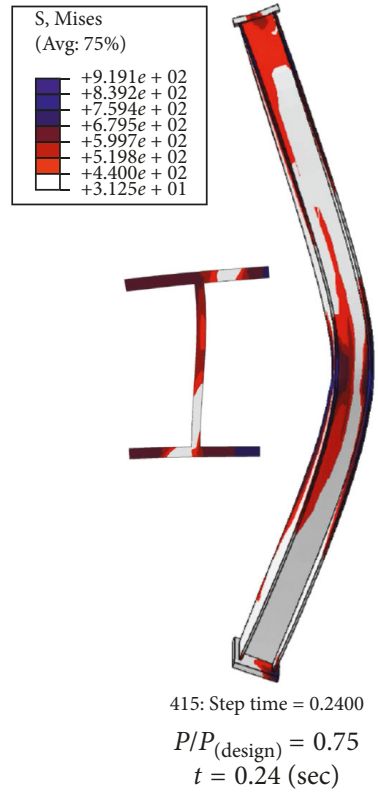

(c)

FIGURE 20: Deformation shape and plastic hinge locations of simply supported column $\mathrm{W} 150 \times 24$ with bending about the major $x$ - $x$ axis.

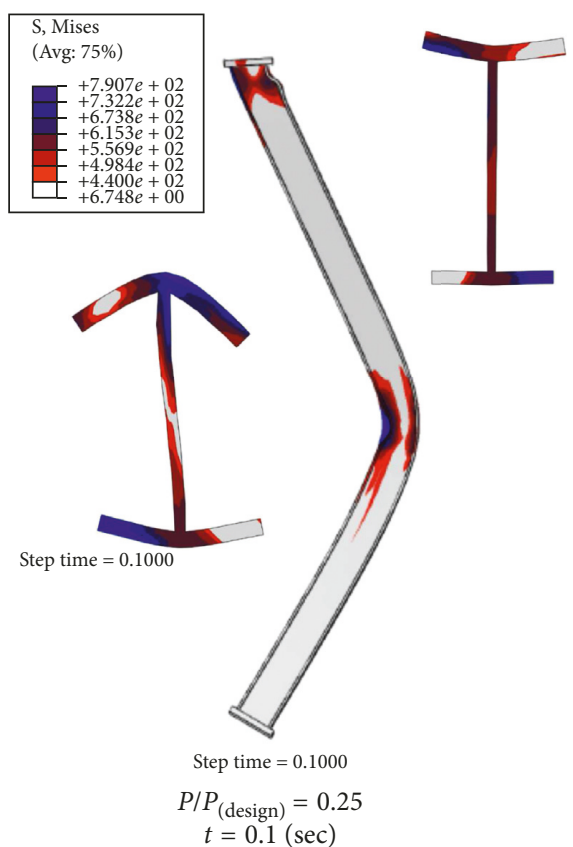

(a)

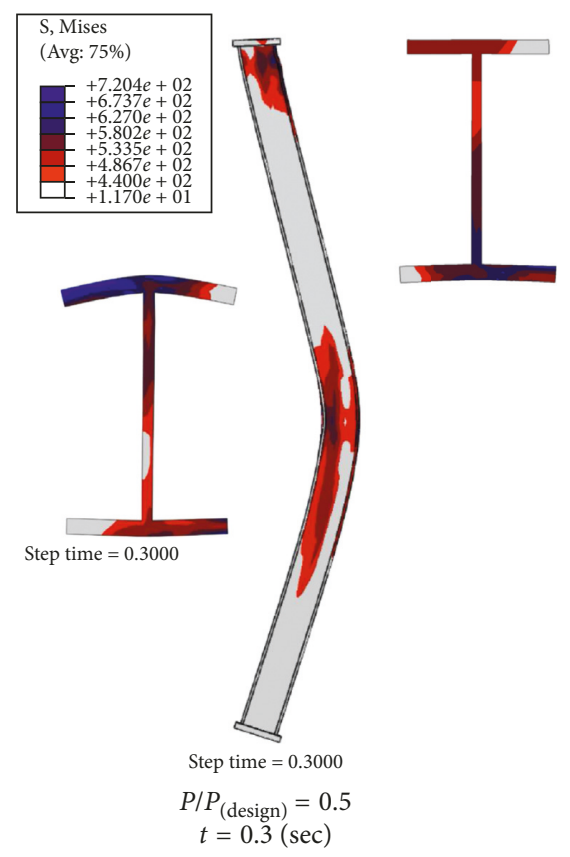

(b)

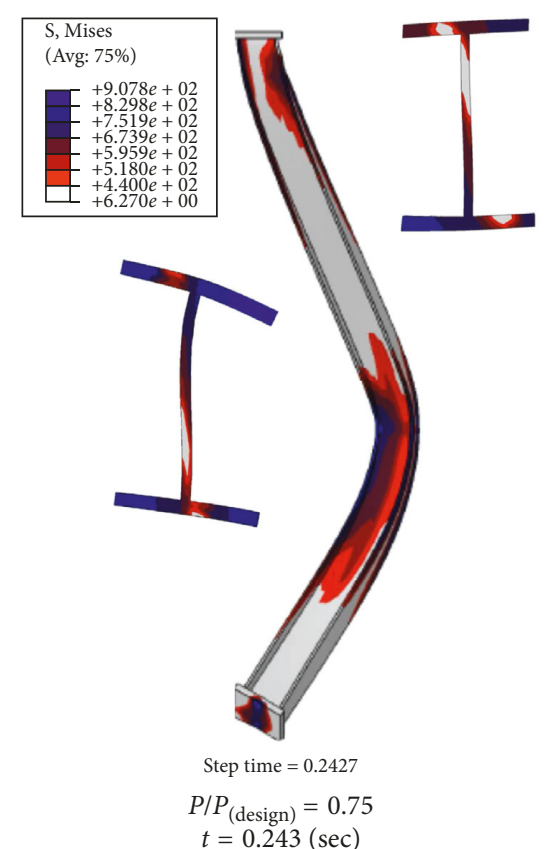

(c)

FIgURE 21: Deformation shape and plastic hinge locations of propped cantilever column W $150 \times 24$ with bending about the major $x$ - $x$ axis.

compression flange or at the section web before column failure. To investigate whether this scenario has been detected in any of the previously simulated columns, Figure 24 shows the dynamic stress-strain relationship of the steel at the location of the plastic hinges for the columns shown in Figures 20-23. This figure indicates that the yield stress of the columns has been increased from the input value $\left(440 \mathrm{~N} / \mathrm{mm}^{2}\right)$ to values ranging from $500 \mathrm{~N} / \mathrm{mm}^{2}$ to
$800 \mathrm{~N} / \mathrm{mm}^{2}$ depending on the variation of the strain rate values of each column. Comparing the values of the dynamic yield stress in Figure 24 to the dynamic stress distributed over the cross section of the columns shown in Figures 20-23 reveals that most of the columns had not reached the full dynamic yielding capacity when the global failure occurred. Hence, these columns should be classified as noncompact sections under dynamic blast loads [18]. 


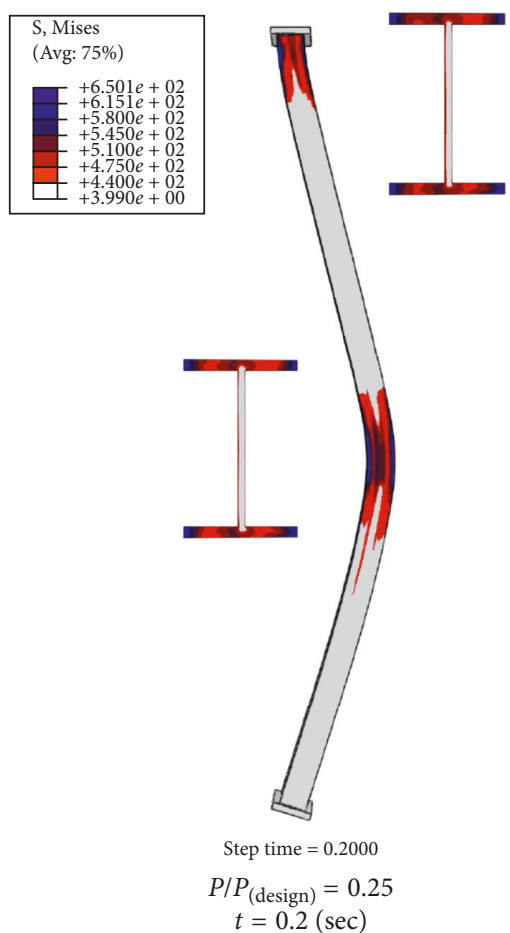

(a)

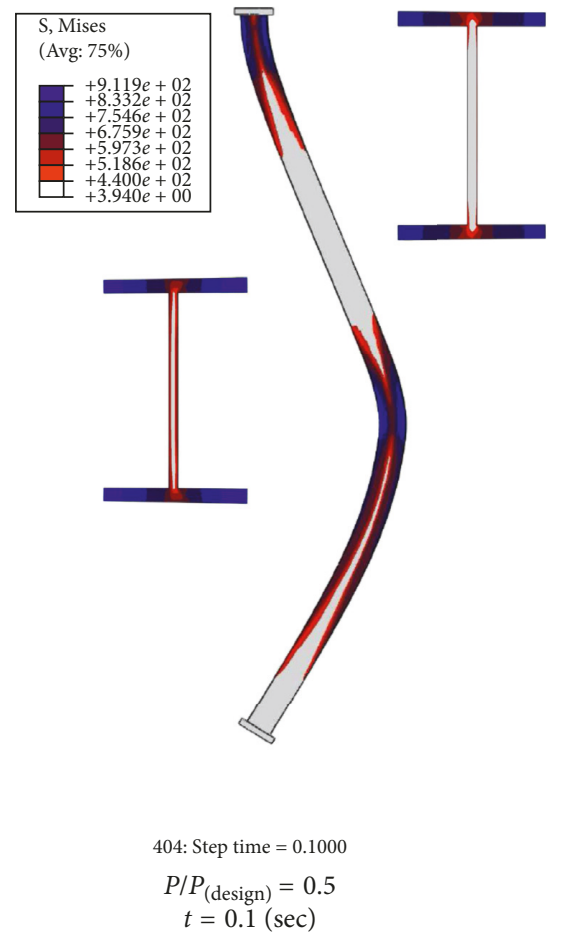

(b)

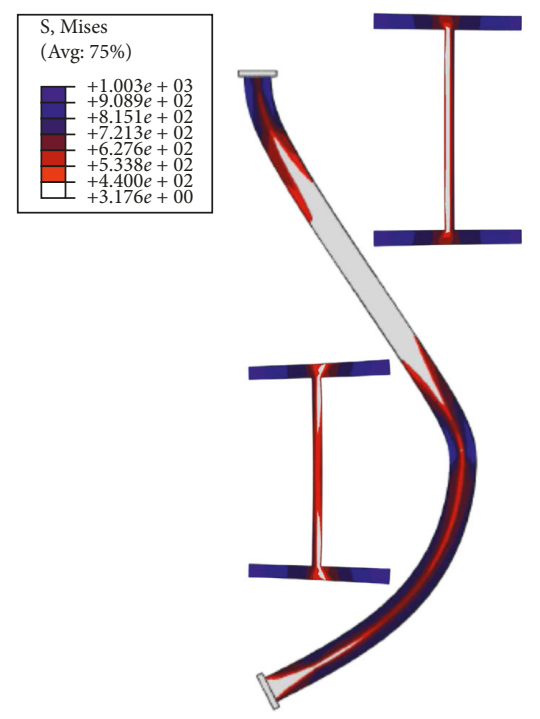

$$
\begin{gathered}
\text { Step time }=0.1000 \\
P / P_{(\text {design })}=0.75 \\
t=0.1(\mathrm{sec})
\end{gathered}
$$

(c)

FIGURE 22: Deformation shape and plastic hinge locations of propped cantilever column W $150 \times 24$ with bending about the minor $y$ - $y$ axis.

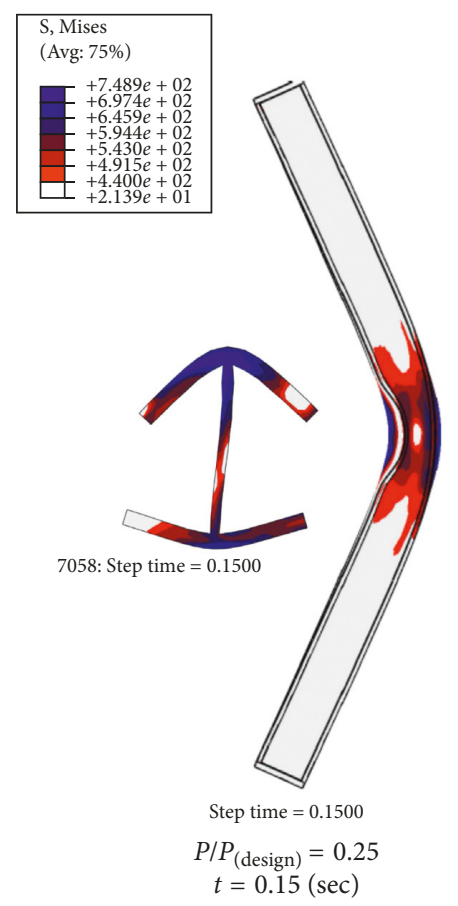

(a)

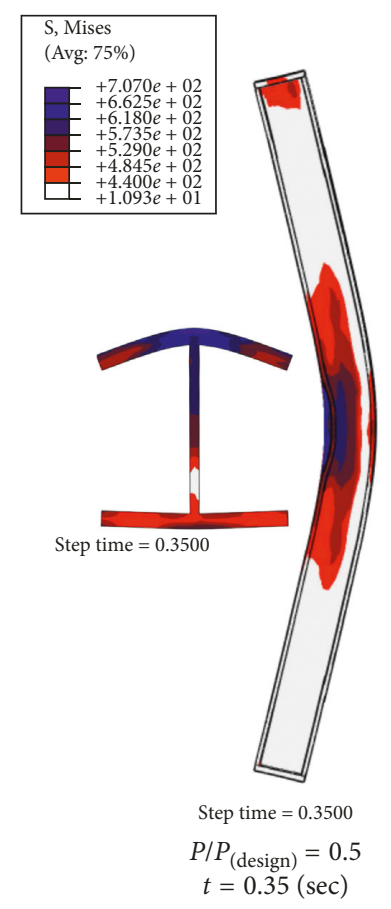

(b)

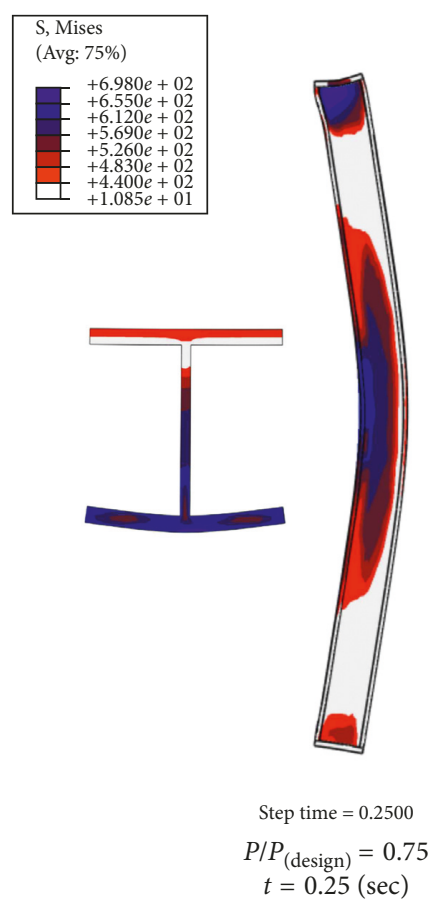

(c)

FIGURE 23: Deformation shape and plastic hinge locations of simply supported steel column W200 $\times 71$ with bending about the major $x$ - $x$ axis. 


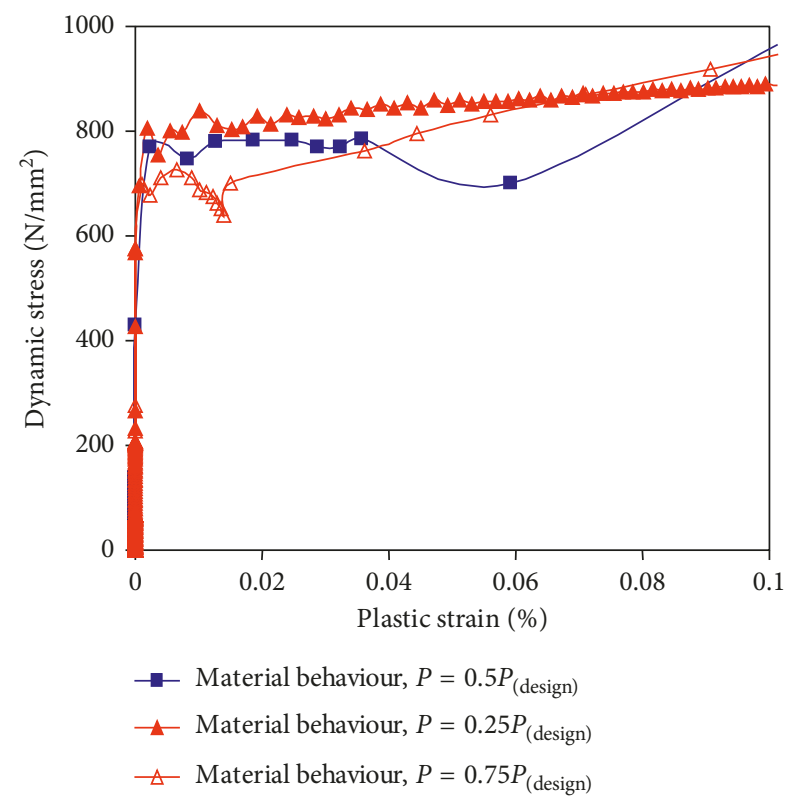

(a)

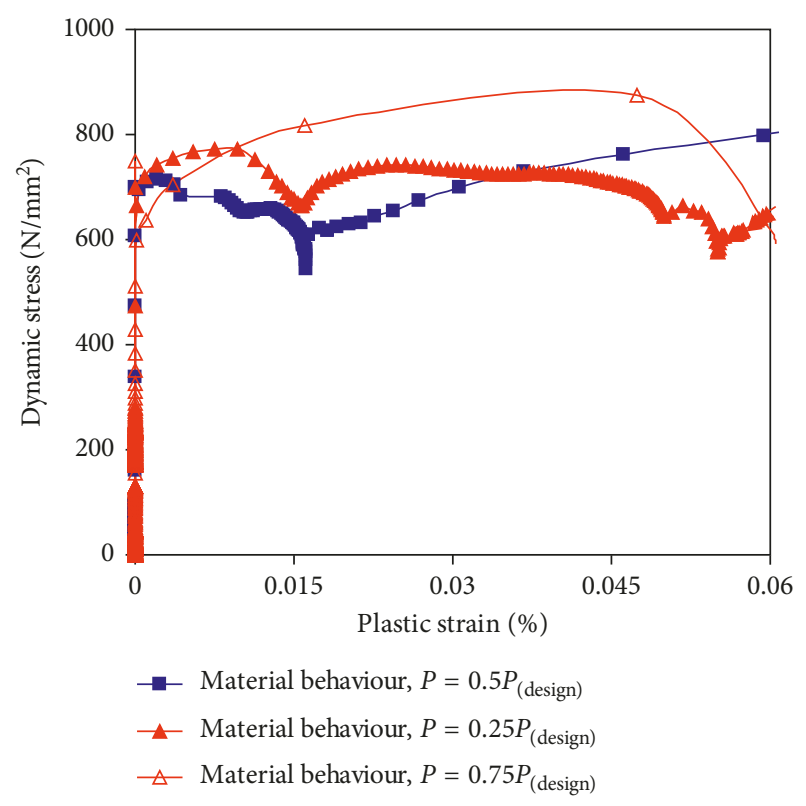

(c)

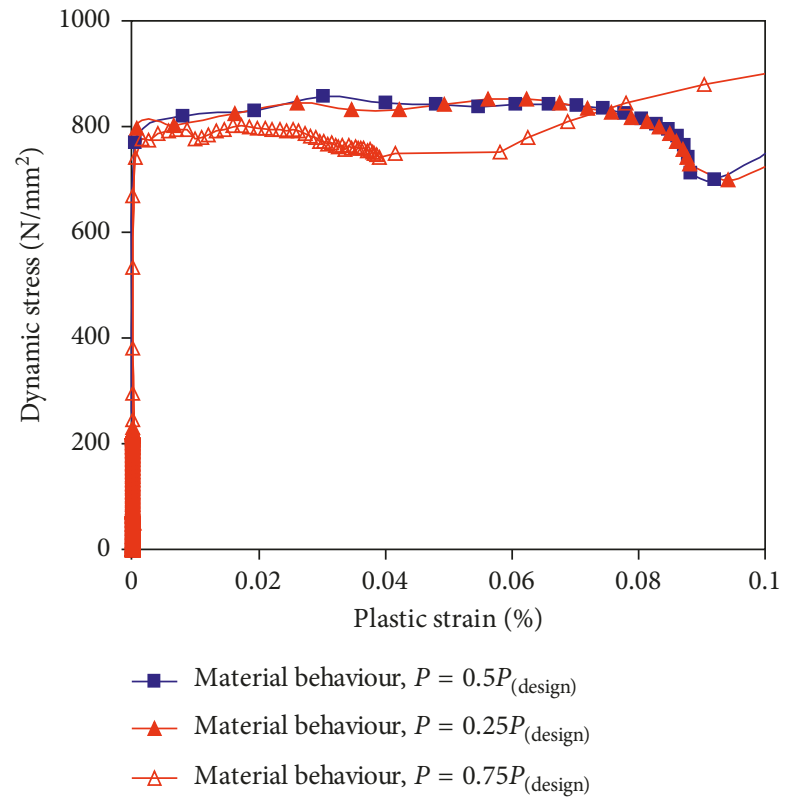

(b)

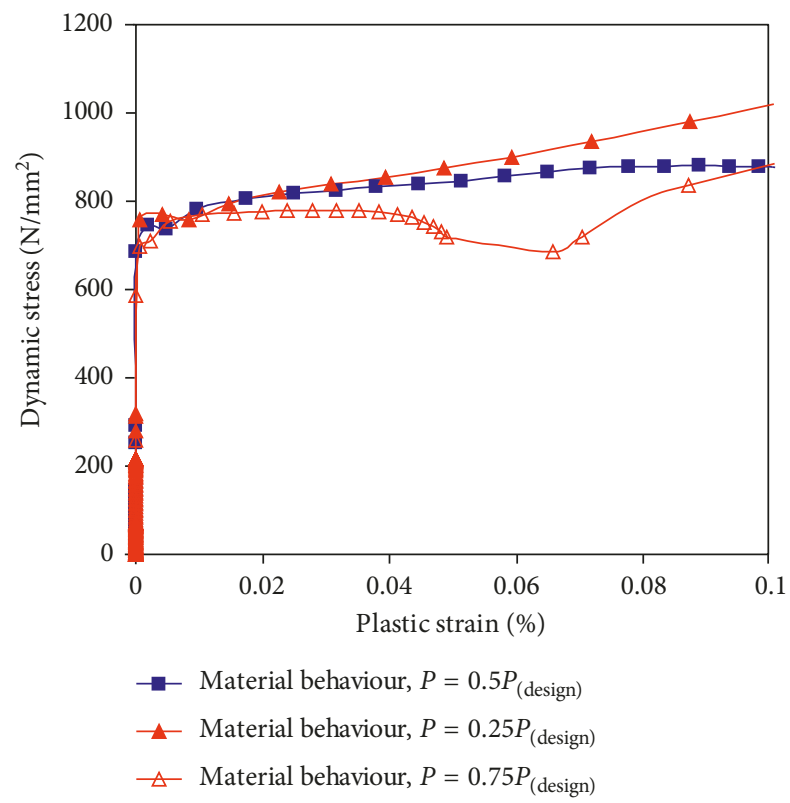

(d)

FIgURe 24: Dynamic stress-plastic strain relationship of the steel at the locations of the plastic hinges. (a) Simply supported W150 $\times 24$ with bending about the major $x$ - $x$ axis. (b) Propped cantilever W $150 \times 24$ with bending about the major $x$ - $x$ axis. (c) Propped cantilever W150 $\times 24$ with bending about the minor $y$ - $y$ axis. (d) Simply supported W200 $\times 71$ with bending about the minor $y$ - $y$ axis.

\section{Analytical Approach}

The parametric study conducted in this research has demonstrated that global instability is the major failure mode for steel columns under blast load and column global failure was mainly dependent on the value of blast impulse and/or blast energy imparted to the column. These two conclusions are crucial and will be used to suggest a simplified analytical method for this particular type of dynamic blast problem. The main goal of this analytical method is to obtain the column axial load-critical blast impulse relationship. The critical blast impulse can be defined as the minimum impulse of the blast pressure that causes the column to lose its global bucking under axial compressive load. The suggested method can be implemented in the design of steel columns that are vulnerable to blast pressure since it can provide a reasonable prediction of the axial load and at the onset of column global failure.

The suggested analytical approach is based on the energy conservation principle with a quasi-static simplification of the column behaviour. The energy balance principle is more appropriate to handle the dynamic blast 


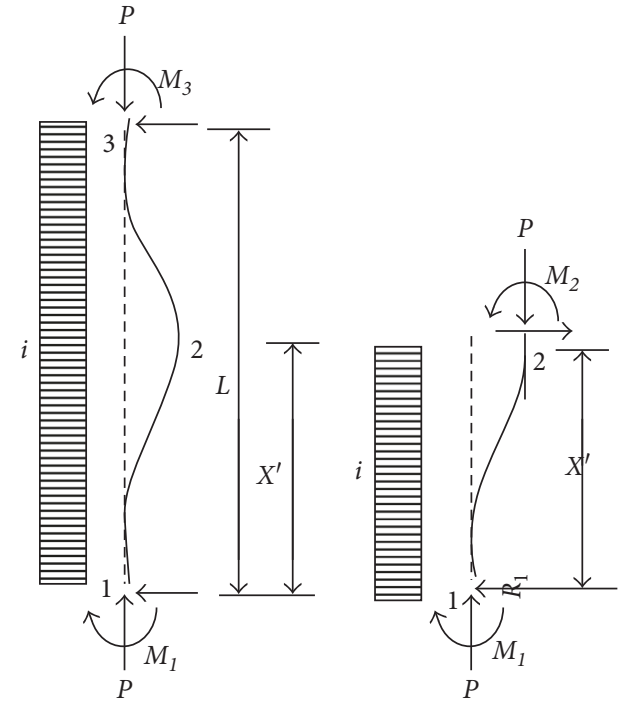

(a)

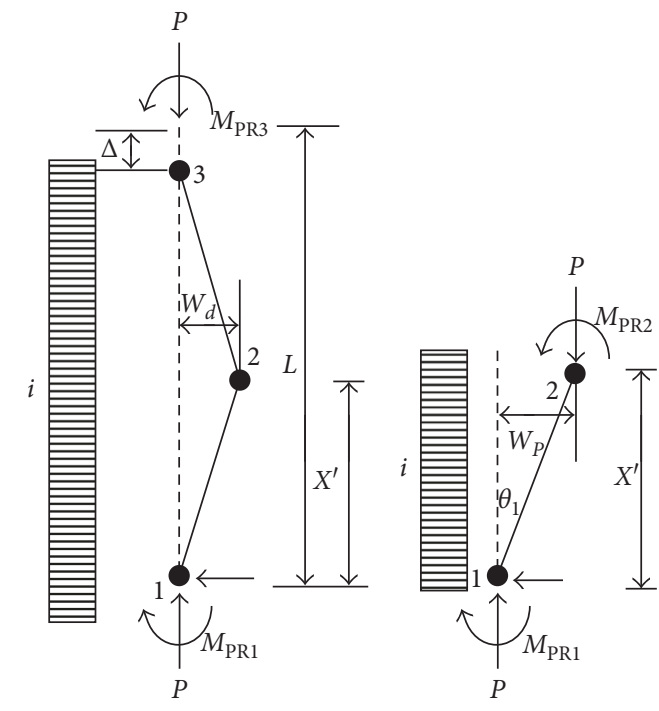

(b)

FIgUre 25: Column deformation shape used in analytical model. (a) Elastic phase. (b) Plastic phase.

problem when the time period of the blast is very short compared to the natural period of the steel column [17]. This section will present the analytical derivations based on the assumptions extracted from the parametric study along with results of validation of the suggested method against numerical simulation.

4.1. Energy Balance Equation. The general energy conservation equation for the structural system under dynamic blast pressure can be described as

$$
I_{\mathrm{E}}+V_{\mathrm{D}}+K_{\mathrm{E}}-W_{\mathrm{K}}=E_{\mathrm{TOTAL}}
$$

where $I_{\mathrm{E}}$ is the internal strain energy due to elastic-plastic deformations, $V_{\mathrm{D}}$ is the viscous dissipation energy, $K_{\mathrm{E}}$ is the residual kinetic energy, $W_{\mathrm{K}}$ is the work done by the external forces, and $E_{\mathrm{TOTAL}}$ is the total blast energy imparted to the structural system.

For the critical situation, the column is at rest; therefore, $K_{\mathrm{E}}=0$. Due to the short duration of the blast load, the viscous dissipation energy at the critical condition is negligible compared to the initial blast energy (i.e., $V_{\mathrm{D}} \approx 0$ ).

Hence, for a column subjected to blast pressure, (2) becomes

$$
\begin{aligned}
I_{\mathrm{E}}-W_{\mathrm{K}} & =E_{\mathrm{TOTAL}} \\
& =\text { total blast energy imparted to the column, } \\
\text { or } I_{\mathrm{E}} & =\text { total blast energy }+W_{\mathrm{K}} .
\end{aligned}
$$

Total blast energy imparted to the column can be expressed by equations listed in Table 4 for the three main cases of column boundary condition.

4.2. Internal (Strain) Energy $\left(I_{\mathrm{E}}\right)$. Al-Thairy and Wang [19] have presented detailed derivations of a simplified equation
TABle 5: Equations for the critical blast impulse.

\begin{tabular}{lc}
\hline Boundary condition & Critical blast impulse \\
\hline Pinned-pinned column & $i_{\mathrm{cr}}=\sqrt{\frac{\left(\pi^{2} m\right) M_{\mathrm{PR}}^{2}}{2 k^{2} L^{2}}\left(\frac{1}{P}-\frac{1}{P_{\mathrm{cr}}}\right)}$ \\
Fixed-fixed column & $i_{\mathrm{cr}}=\sqrt{\frac{(6 m) M_{\mathrm{PR}}^{2}}{k^{2} L^{2}}\left(\frac{1}{P}-\frac{1}{P_{\mathrm{cr}}}\right)}$ \\
Fixed-pinned column & $i_{\mathrm{cr}}=\sqrt{\frac{(5.51 m) M_{\mathrm{PR}}^{2}}{k^{2} L^{2}}\left(\frac{1}{P}-\frac{1}{P_{\mathrm{cr}}}\right)}$ \\
\hline
\end{tabular}

to determine the energy absorbed by elastic and plastic deformations of steel columns subjected to rigid body impact. In their study, Al-Thairy and Wang have assumed that the elastic buckling mode is the main elastic deformation shape of the column, and the middle plastic was at the position of the maximum lateral deformation of the column according to the elastic buckling mode. However, the parametric study conducted in the present paper has shown that the assumptions used by Al-Thairy and Wang [19] for steel column under transverse rigid body impact can be adopted for steel columns under transverse blast pressure. It has also assumed that the stress-strain behaviour of steel is linear elastic perfectly plastic, and the column cross sections have large rotation capacities, and the strain rate effect have been neglected to provide more conservative results. Figure 25 illustrates the assumed deformation shape of the steel column in the suggested analytical model.

Based on the above assumptions, the strain energy $\left(I_{\mathrm{E}}\right)$ of the steel column under an axial compressive static load $P$ higher than $25 \%$ of the design axial static compressive load of the column (i.e., $P \geq 25 \% P_{\text {Design }}$ ) is determined from the following equation which can be used for all column boundary conditions mentioned in Table 4 [19]: 


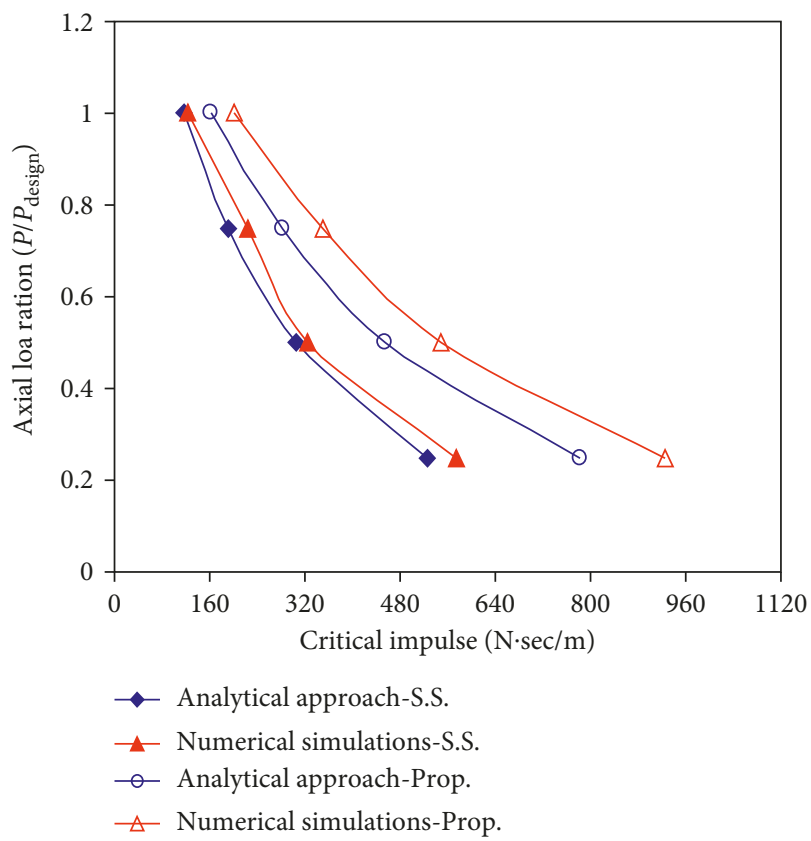

(a)

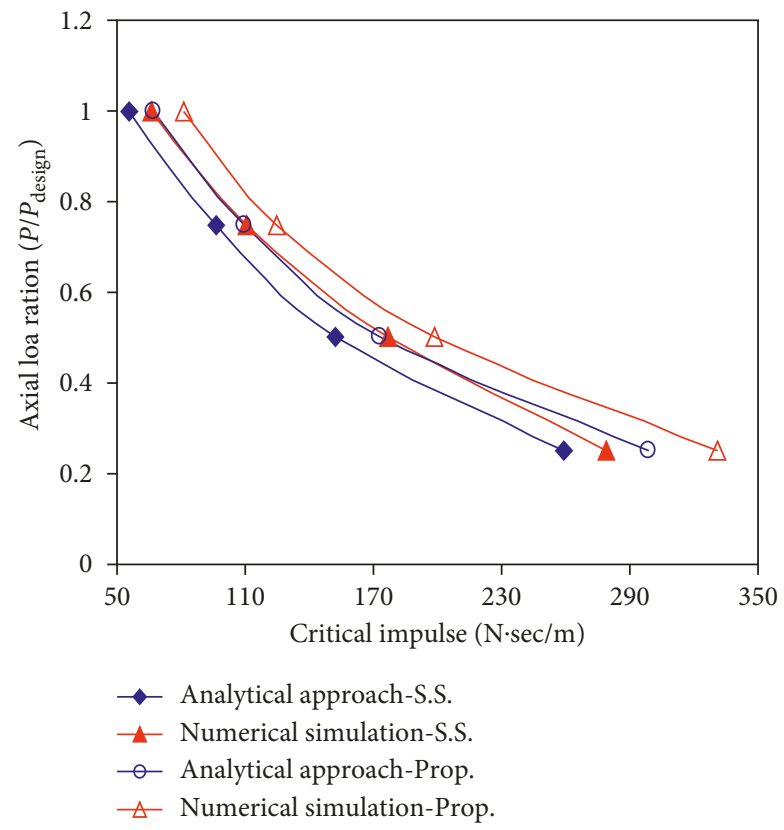

(b)

FIgURE 26: Comparison between analytical method and ABAQUS predictions of critical impulse-axial force curve for steel column section W150 $\times 24$ with simply supported (S.S.) and propped cantilever (Prop.) boundary conditions and with blast pressure to cause bending about major and minor axes of the column.

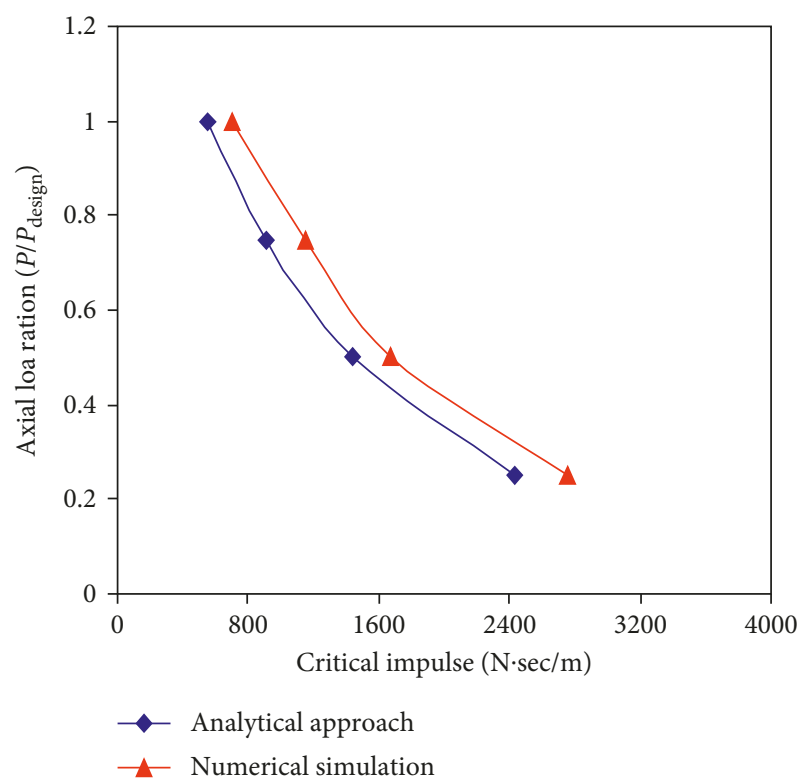

FIGURE 27: Comparison between analytical method and ABAQUS predictions of critical impulse-axial force curve for simply supported steel column section W200 $\times 71$ with blast pressure to cause bending about major axis of the column.

$$
I_{\mathrm{E}}=\frac{4 M_{\mathrm{PR}}^{2}}{k^{2} L}\left(\frac{1}{P}-\frac{1}{2 P_{\mathrm{cr}}}\right),
$$

where $M_{\mathrm{PR}}$ is the reduced plastic moment capacity of the steel column section, $L$ is the column length, and $P_{\text {cr }}$ and $k$ are the Euler buckling load and the effective length factor of the column, respectively.

4.3. External Work. The work done by the axial load can be expressed by [19]

$$
\therefore W_{\mathrm{K}}=\frac{P \times L \times W_{\mathrm{cr}}^{2}}{2 x^{\prime}\left(L-x^{\prime}\right)}
$$

where $x^{\prime}$ is the middle plastic hinge location within the column length which can be taken as the position of the maximum lateral displacement of the column $(0.5 \times L$ for simply supported columns and about $0.6 \times L$ from the position of the fixed support for propped cantilever columns) $[9,13] . W_{\text {cr }}$ is the maximum displacement at the middle plastic hinge location determined by

$$
W_{\text {cr }}=\frac{M_{\mathrm{PR}}}{k P}
$$

Substituting the value of $W_{\mathrm{cr}}$ from (6) into (5) yields the following simple and general equation:

$$
\therefore W_{\mathrm{K}}=\frac{2 M_{\mathrm{PR}}^{2}}{k^{2} P L} \text {. }
$$

4.4. General Energy Balance Equation. Now, substituting the strain energy absorbed by the column (4) and the work done by the axial compressive force (7) and the kinetic energy imparted to the column from the blast pressure (see $(*)$ $(* * *)$ in Table 4$)$ into (3), the following generalized equation is determined: 


$$
\frac{4 M_{\mathrm{PR}}^{2}}{k^{2} L}\left(\frac{1}{P}-\frac{1}{2 P_{\mathrm{cr}}}\right)=\frac{4 L}{\pi^{2} m} i_{\mathrm{cr}}^{2}+\frac{2 M_{\mathrm{PR}}^{2}}{k^{2} P L} .
$$

The critical blast impulse $i_{\text {cr }}$ at the threshold of column global failure can be determined from the above equation as

$$
i_{\mathrm{cr}}=\sqrt{\frac{\left(\pi^{2} m\right) M_{\mathrm{PR}}^{2}}{2 k^{2} L^{2}}\left(\frac{1}{P}-\frac{1}{P_{\mathrm{cr}}}\right)} .
$$

Table 5 shows the critical blast impulse equations for the other cases of column boundary condition.

4.5. Validation. The suggested analytical method has been validated by comparing the column axial force-critical blast impulse curves calculated by the analytical method with that predicted from numerical simulations. The two steel columns used in the parametric study of this research were used in the validation examples with same loading ratios, geometrical parameters, and material properties. However, the steel stress-strain relationship was simulated to be elastic perfectly plastic with a modulus of elasticity $206000 \mathrm{~N} / \mathrm{mm}^{2}$ and a yield strength $440 \mathrm{~N} / \mathrm{mm}^{2}$ to match the assumption used in the derivations.

Figures 26 and 27 compare the critical blast impulseaxial force curves between the analytical and numerical simulation results for the two column sections $(\mathrm{W} 150 \times 24$ and W200 $\times 71$ ), two different boundary conditions (simply supported and fix-ended) and with blast directions to cause bending about the major and minor axes of the column. As can be shown from these figures, very good correlation is obtained between the analytical and numerical simulation results. The agreement between the analytical and numerical results is better for the simply supported column than the propped column. For the simply supported column, the main deformations developed at the column when failure occurs are global deformations as assumed in derivations. However, for the propped column, shear deformations were developed at the fixed support as demonstrated in the parametric study of this paper, which could absorb part of the blast energy. Nevertheless, as the suggested analytical approach gives more conservative results compared with the numerical simulation results for both cases of column boundary condition, the analytical results can be considered acceptable for design purposes.

\section{Conclusions}

This study has presented numerical simulations of the behaviour and failure of wide-flange steel columns subjected to dynamic blast loads. First, a numerical model has been put forward using the dynamic finite element package ABAQUS/Explicit. The suggested numerical model has been validated against the experimental tests conducted by Nassr et al. [4] on full-scale steel columns subjected to air blast loads induced by an explosion. The validations results have shown the reliability of the suggested model to simulate such a dynamic problem. The validated model has been implemented to conduct a parametric study to investigate the effect of several important parameters on the behaviour and failure modes and conditions of steel columns subjected to blast load. These parameters include the blast impulse, the blast energy, the blast pressure, the blast duration, the blast direction, the column boundary condition, and the column slenderness ratio. The following conclusions have been drawn from the results of the parametric study:

(a) Global plastic instability is the main failure pattern of steel columns under dynamic blast load with a considerable value of static axial compressive load (i.e., $>0.25$ of the design axial load).

(b) When the applied static axial load is low (i.e., $\leq 0.25$ of the design axial load), shear failure can also occur at the column fixed supports.

(c) The critical blast impulse and the blast-induced kinetic energy can be used to define the column failure conditions and set an upper limit of the column strength. For the same value of the critical blast impulse, different combinations of blast pressure and time duration had minor effects on column failure.

(d) The plastic resistance of the steel columns increases when the columns are subjected to dynamic blast loads due to the strain rate sensitivity effect. However, local buckling of the compression flange may occur before the section reaches the full dynamic plastic resistance in the plastic mechanism collapse mode. Should the strain rate effect have to be considered in an analytical method, the reduction in dynamic plastic moment capacity of the column at failure must be considered.

The study has also presented a simplified method to predict the critical blast impulse at which a steel column losses its global stability when subjected to transverse blast pressure. The suggested method utilizes the energy conservation principle with quasi-static simplification of the column response. The column is assumed to fail under global buckling following the plastic hinge mechanism. Comparison between the critical impulse-axial force curves obtained from the proposed method and that extracted from numerical simulations indicates the validity and accuracy of the presented method.

\section{Conflicts of Interest}

The author declares that there are no conflicts of interest.

\section{References}

[1] Eurocode 1, Actions on Structures-Part 1-7: General Actions-Accidental Actions. BS EN 1991-1-7, pp. 31-32, European Committee for Standardization, Incorporating corrigendum, Brussels, Belgium, 2010.

[2] USDOD, Structures to Resist the Effects of Accidental Explosions. Document No. UFC 3-340-02, US Department of Defense, Washington, DC, USA, 2008.

[3] A. A. Nassr, A. G. Razaqpur, M. J. Tait, M. Campidelli, and S. Foo, "Strength and stability of steel beam columns under blast load," International Journal of Impact Engineering, vol. 55, pp. 34-48, 2013.

[4] A. A. Nassr, A. G. Razaqpur, M. J. Tait, M. Campidelli, and S. Foo, "Dynamic response of steel columns subjected to blast loading," Journal of Structural Engineering, vol. 140, no. 7, p. 04014036, 2014. 
[5] ASCE, Design of Blast Resistant Buildings in Petrochemical Facilities, Task Committee on Blast Resistant Design, ASCE, New York, NY, USA, 1997.

[6] S. B. Menkes and H. J. Opat, "Broken beams," Experimental Mechanics, vol. 13, pp. 480-486, 1973.

[7] F. L. Chen and T. X. Yu, "Influence of axial pre-load on plastic failure of beams subjected to transverse dynamic load," Key Engineering Materials, vol. 117-180, pp. 255-260, 2000.

[8] H. Chen and J. Y. Liew, "Explosion and fire analysis of steel frames using a mixed element approach," Journal of Engineering Mechanics, vol. 131, no. 6, pp. 606-616, 2005.

[9] R. L. Shope, "Response of wide flange steel columns subjected to constant axial load and lateral blast load," Ph.D. thesis, The Faculty of the Virginia Polytechnic Institute and State University, Blacksburg, VA, USA, 2006.

[10] K. Lee, T. Kim, and J. Kim, "Local response of W-shaped steel columns under blast loading," Structural Engineering and Mechanics, vol. 31, no. 1, pp. 25-38, 2009.

[11] H. Al-Thairy, "Modified single degree of freedom method for the analysis of building steel columns subjected to explosion induced blast load," International Journal of Impact Engineering, vol. 94, pp. 120-133, 2016.

[12] Simulia, Analysis User's Manual, Simulia, Dassault Systèmes, Providence, RI, USA, 6.10 edition, 2012.

[13] H. Al-Thairy and Y. C. Wang, "A numerical study of the behaviour and failure modes of axially compressed steel columns subjected to transverse impact," International Journal of Impact Engineering, vol. 38, no. 8-9, pp. 732-744, 2011.

[14] N. Jones, Structural Impact, Cambridge University Press, Cambridge, UK, 2nd edition, 1997.

[15] J. L. Humar, Dynamics of Structures, Library of Congress Cataloging in Publication Data, Lisse, Netherlands, 2nd edition, 2002.

[16] AISC, Manual of Steel Construction. Load and Resistance Factor Design (LRFD), American Institute of Steel Construction, Chicago, IL, USA, 13th edition, 2005.

[17] J. M. Biggs, Introduction to Structural Dynamics, McGrawHill, New York, NY, USA, 1964.

[18] J. Y. R. Liew, "Survivability of steel frame structures subject to blast and fire," Journal of Constructional Steel Research, vol. 64, no. 7-8, pp. 854-866, 2008.

[19] H. Al-Thairy and Y. C. Wang, "A simplified analytical method for predicting the critical velocity of transverse rigid body impact on steel columns," International Journal of Impact Engineering, vol. 58, pp. 39-54, 2013.

[20] G. R. Cowper and P. S. Symonds, "Strain hardening and strain rate effect in the impact loading of cantilever beams," Division of Applied Mathematics, Brown University, Providence, RI, USA, Report no. 28, 1957. 


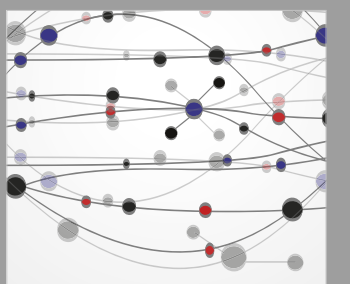

The Scientific World Journal
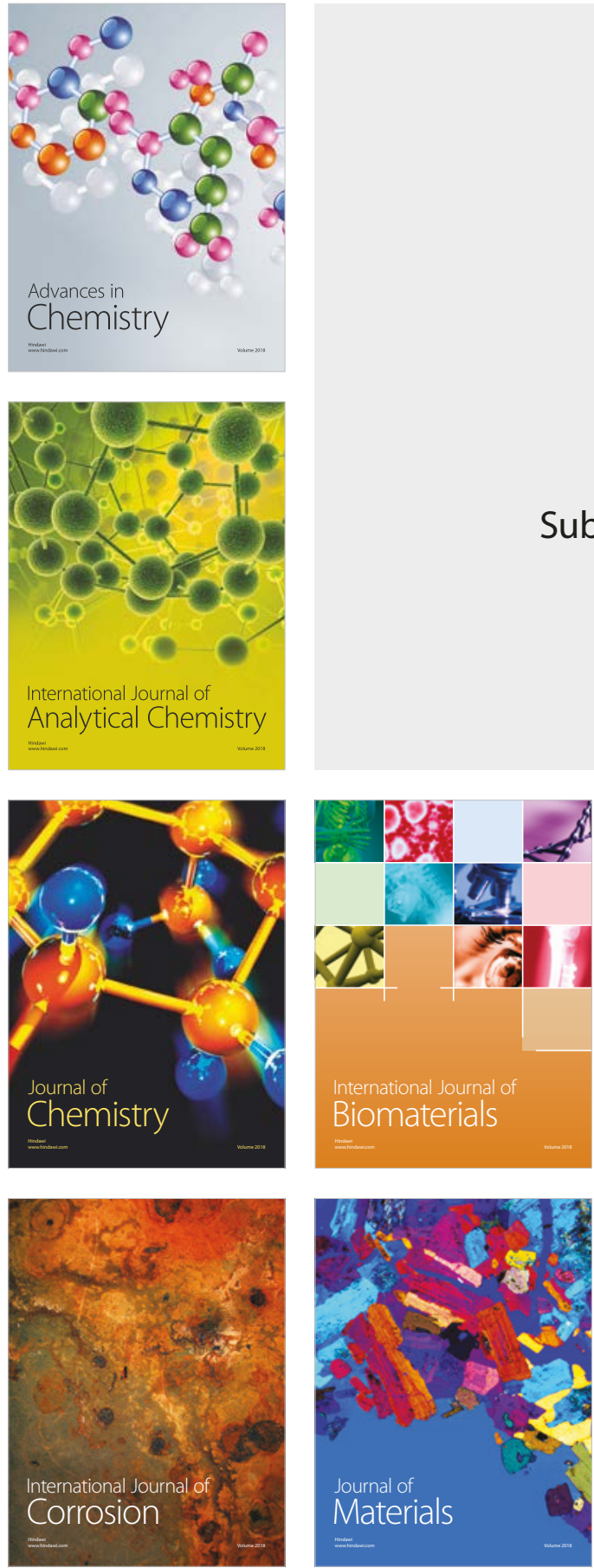

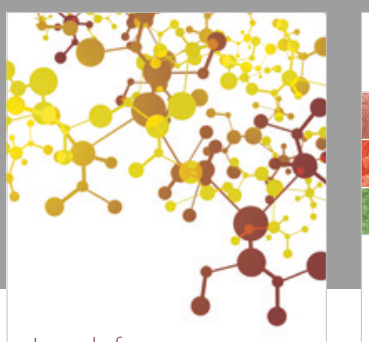

Journal of

Applied Chemistry
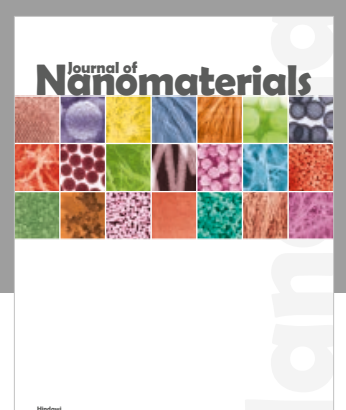

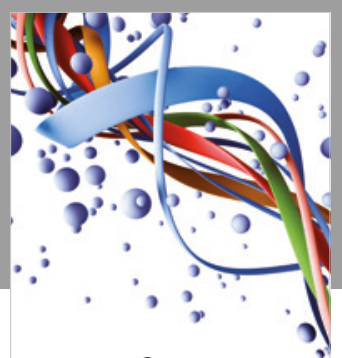

Scientifica

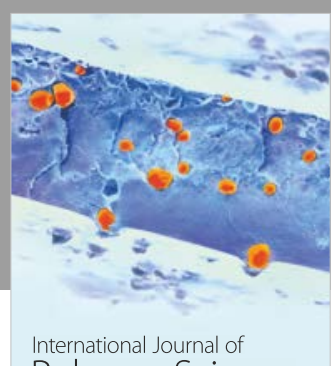

Polymer Science

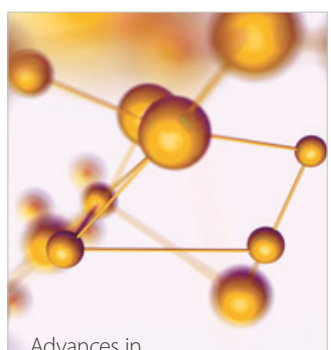

Physical Chemistry
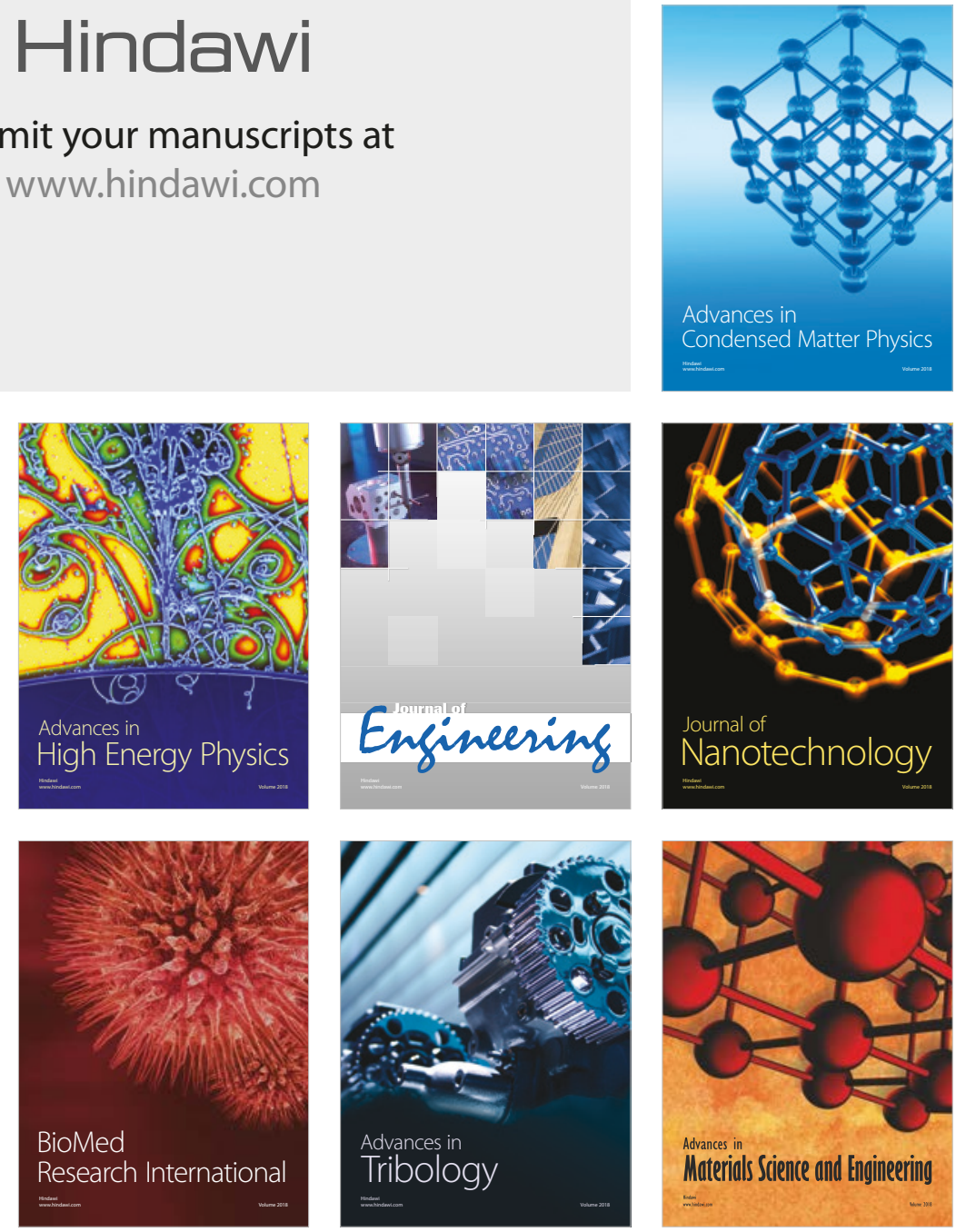